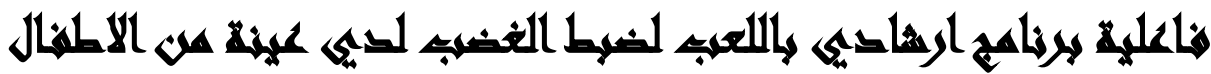

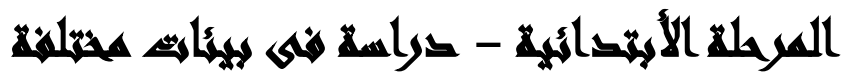

$[1 \cdot]$

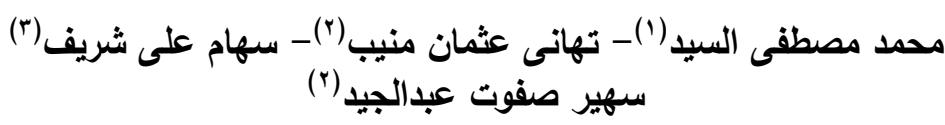

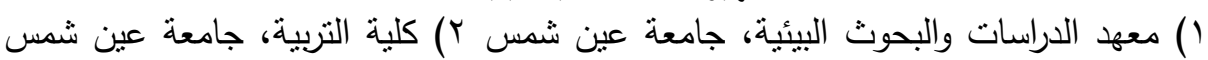

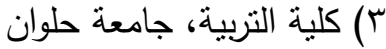

\section{المستخلم:}

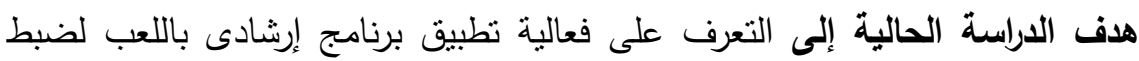

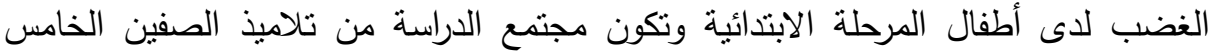
والسادس وهما من مدرستين الاولى مدرسة عباس العقاد بمحافظة الاسماعيلية (كبيئة حضرية الإنة

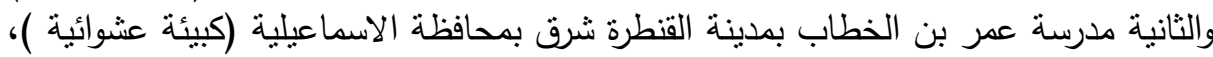
وتكونت عينة الدراسة من أربعة مجموعات الاولى هي البيئة العشوائية، تكونت البيئة العشوائية

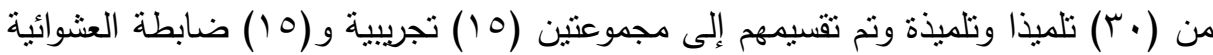

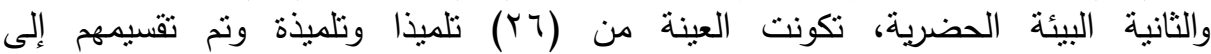

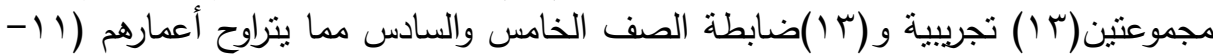

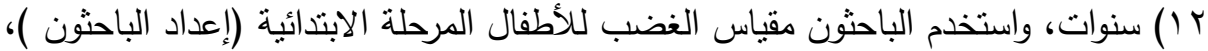

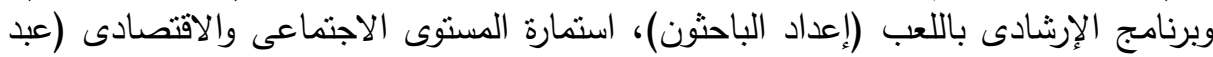

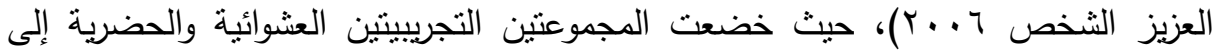

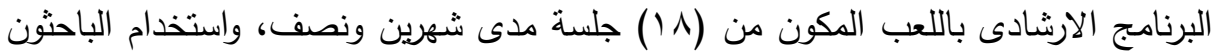

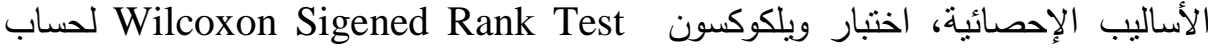

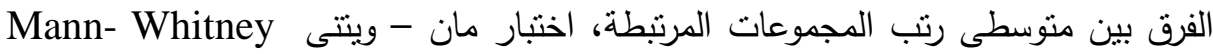

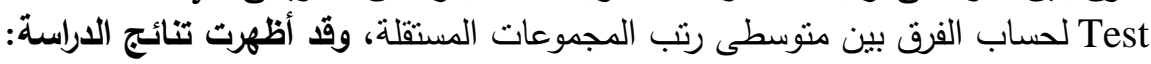

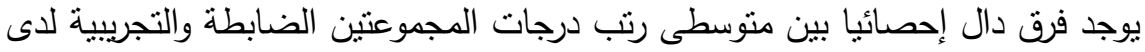

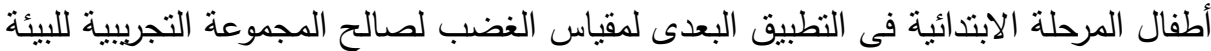

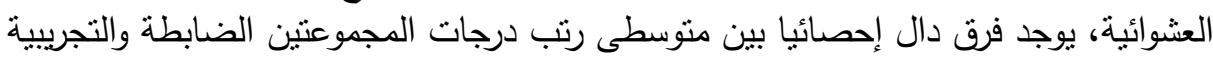

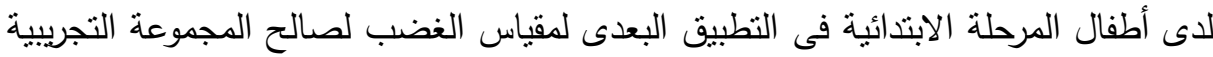

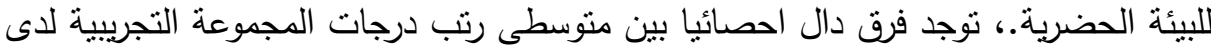
أطفال المرحلة الابتدائية فى التطبيقين القبلى والبعدى لمقياس الغضب بعد بتى تطبيق البرنامج

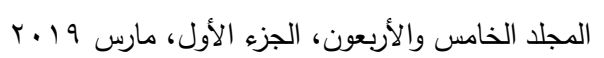


لصالح التطبيق البعدى للبيئة العشوائية. نوجد فرق دال احصائيا بين منوسطى رتب درجات

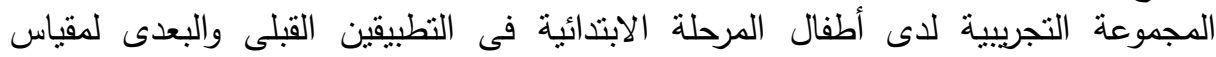

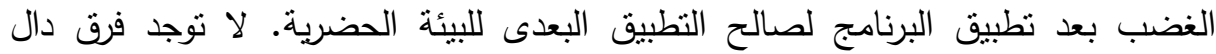

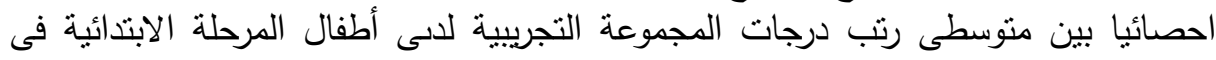

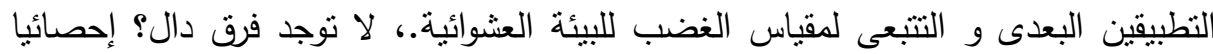
بين منوسطى رتب درجات المجموعة التجريبية لدى أطفال المرحلة الابتدائية فى التطبيقين

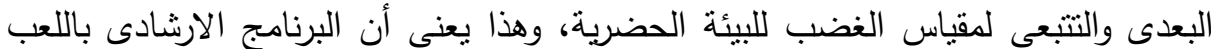

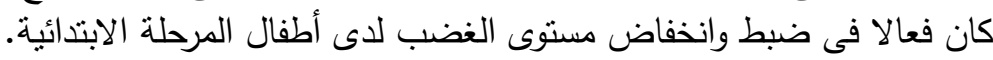
وتوصى الداسة: - أهمية تطوير البرامج الارشادية باللعب سواء كانت جماعية أو فرديه لتحسين التعبير عن المشاعر بطريقة الصحيحه. - استخدام البرامج الارشادية باللعب كإجراء وقائى ونمائى وعلاجى مع المشكلات الأخرى غير الغضب لدى الاطفال المرحلة الابتدائية.

\section{$\cos$}

إن الإهتمام برعاية الطفولة هدف من أهداف التى تسعى الدولة إلى تحقيقها فرعاية طفل

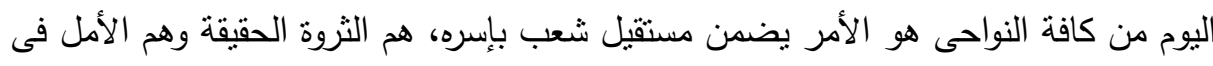
الحاضر والمستقبل ويشكلون •V\% (أقل من 10 سنة ) من مجموعة السكان حاليا وهم

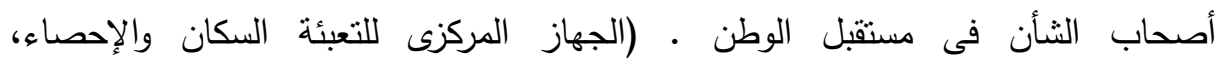

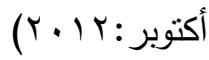

ومن الملاحظ بشكل عام أن جميع الأطفال يمرون بفترات من السلوكيات والأنفعالات

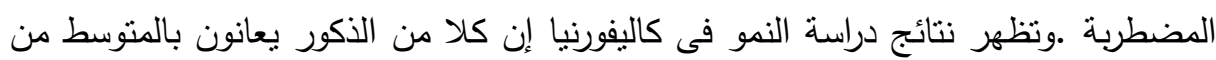
خمس إلى ست مشكلات فى أى وقت خلا مرحلة ماقبل المدرسة والمدرسة الأبتدائية وتتخفض درجة أنتشار هذه المشكلات السلوكية مع التقدم فى العمر بالنسبة الأطفال فى سن فن فئل

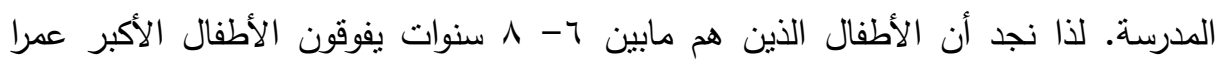

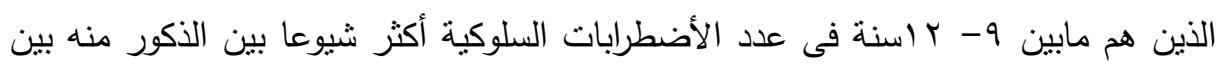

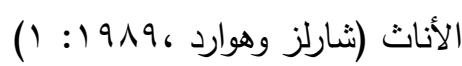


ولقد شهدت العقود الأخيرة ازدياد موجه الغضب وأنتشار العدوان إلى حد كبير بين

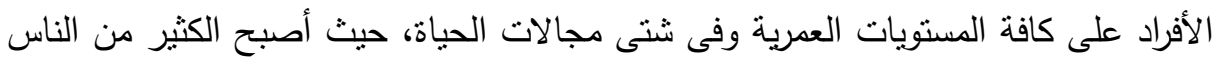
فى الغضب دائم وتوتر وقلق ويمارسون العدوان .وقد يعزو ذلك إلى تعقد الحباة الاجنماعية

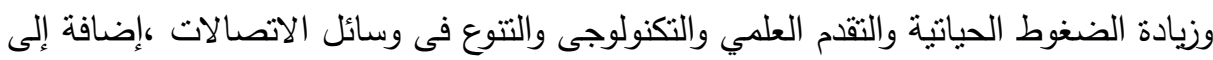

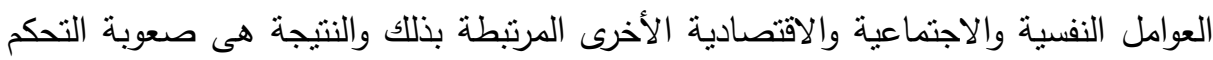

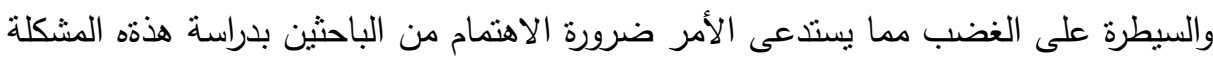

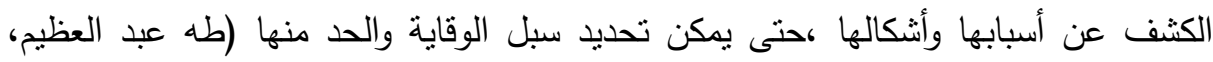
$(1 \cdot: T \cdot Y$

ومن هنا تأتى أهمية التذخل العلاجى للأطفال قبل أن تتعق مشكلاتهم واضطراباتهم

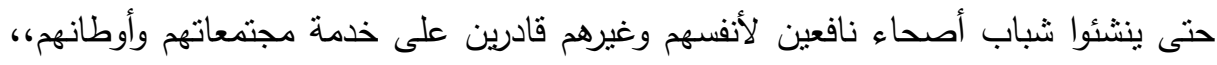

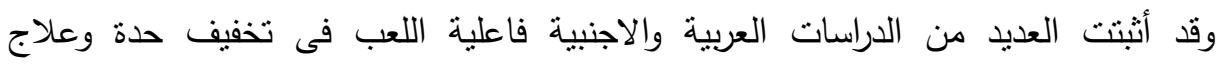
الاضطرابات السلوكية والانفعالية عند الأطفال، فهناك من الدراسات ما أنتبت فاعلية اللعب التبله

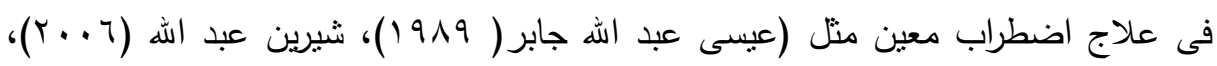

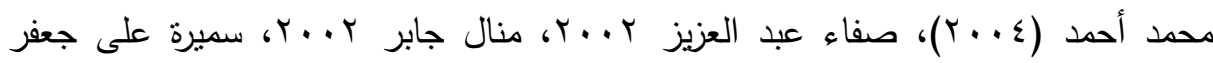

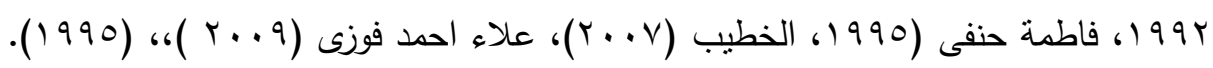
Kaduson \& Finnerty

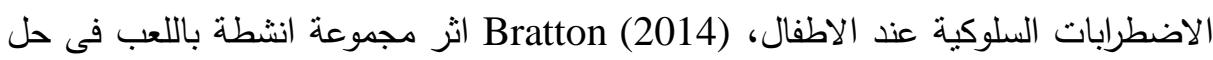

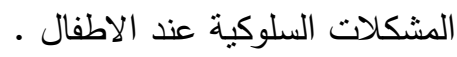

وفى ضوء ما سبق سوف يتتاول هذا البحث فعالية برنامج إرشادى باللعب لضبط

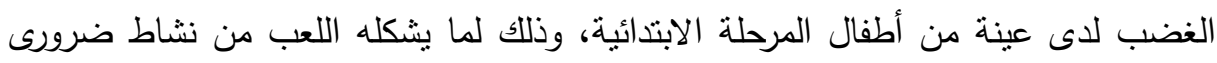
ومهم للتلاميذ فى هذه المرحلة العمرية فضلا عن أن البرنامج الارشادية لها دور فى إناحة الفرصة للتناميذ للتفاعل مع أقرانهم وزيادة السلوك الاجتماعى لديهم. 


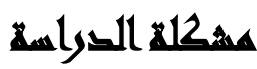

وتتنوع اضرار الغضب بين اضرار صحية منل الصداع والنوبات القلبية وبين الإقدام

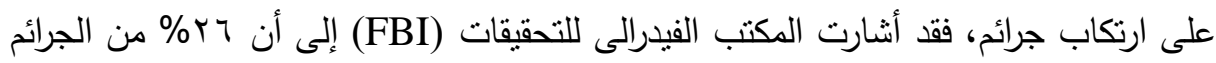
فى الولايات المتحده الامريكية من منشؤها حالات انفعاليه تسبب الثوره والصراخ والثجار

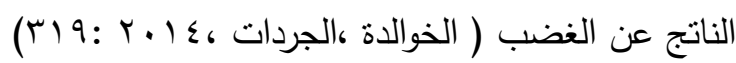

فى دراسة أجارها المركز الوطنى الامريكى لاحصاءات التعليم حول العنف والانضباط

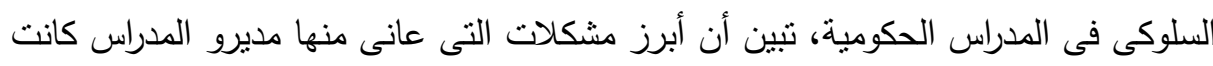

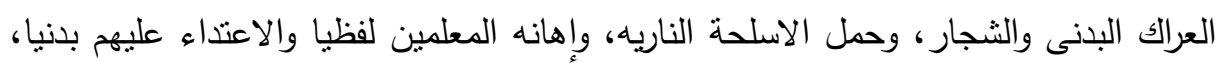

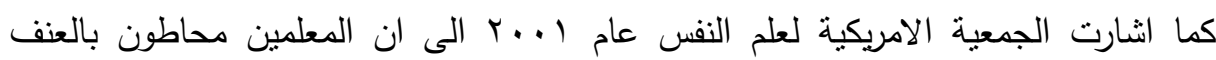

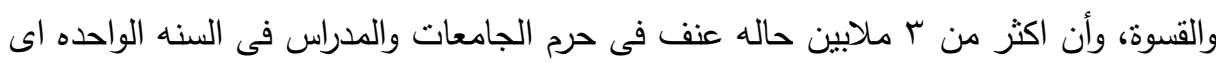
مايعادل 17 الف حاله عنف فى اليوم الواحد أو حاله عنف كل ج ج ثوان ( وسام، نسيمة، (I) TیE: Y. 1T

ويشير مركز رشد التخصصى أن 99\%من الجراثم والمشاكل التي تحدث بين الناس في

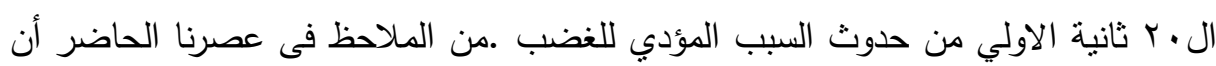
انفعال الغضب لدى الأطفال وعدم التعبير عنه بطريقة سليمة أصبح مشكلة اجتماعية خطيرة ،فكل جيل يظهر سلوكا أسوا من الجيل السابق، وذلك بسبب الأوضاع الاجنماعية والتقافية

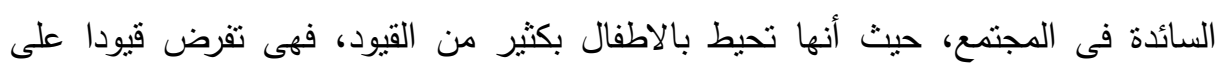

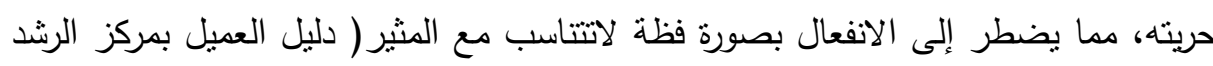
التخصصى:r (r) ولم يجد الباحثون دراسات اهتمت باللعب فى ضبط الغضب لدى المرحلة الابتدائية؟ مما دفع الباحث إلى دراسة اللعب فى ضبط الغضب نحو العملية التعليمية خاصة المرحلة

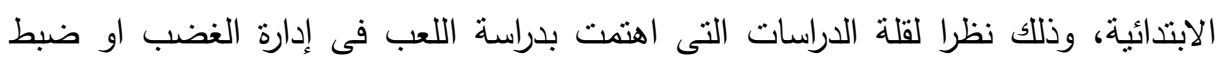
الغضب للمرحلة الابتدائية (فى حدود علم الباحث ) وقد اهتمت الدراسات العربية والأجنيبة

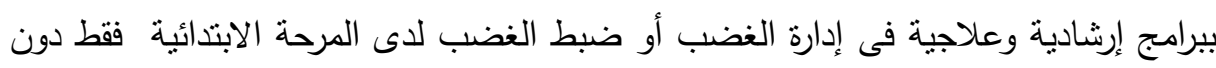
الاهتمام ببرامج إرشادية أو علاجية باللعب فى ضبط الغوادية الغضب إنب لدى المرحلة الابتدائية. 


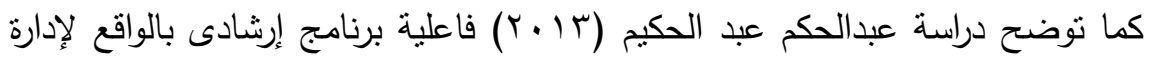
الغضب لدى عينة من طلاب المرحلة الابتدائية . وأسفرت النتائج إلى فعالية البرنامج

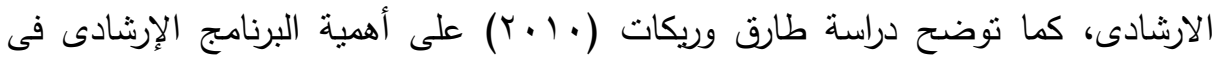

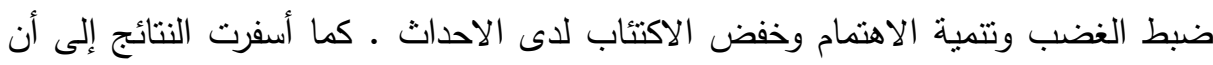

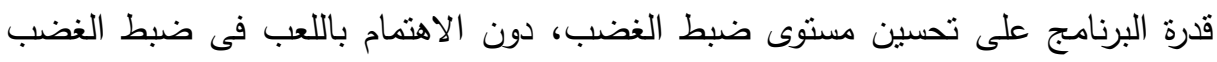

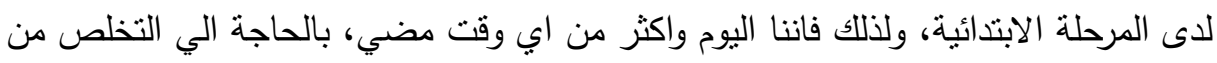

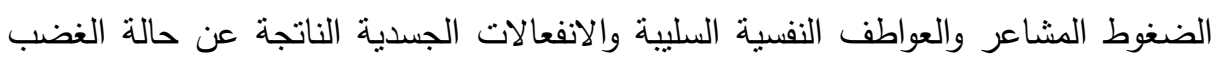
خاصا عند الاطفال في المرحلة الابتدائية . فى ضوء ماسبق يمكن تحديد مشكلة الدراسة فى ولى

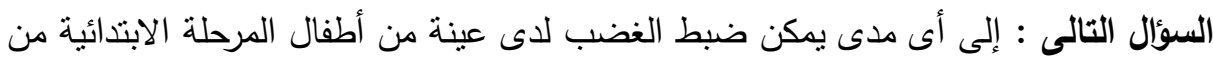

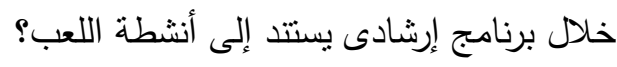

\section{أهمية الصراسما}

الأهمية النظرية: - الناية

1-اهية المتغيرات التى تتاولها الدراسة ،وهى ضبط الغضب، اللعب لدى اطفال المرحلة

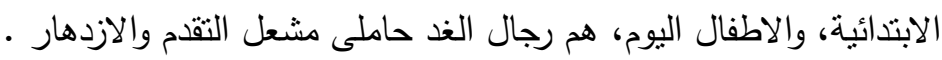

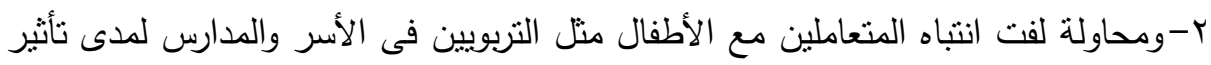
برنامج إرشادى باللعب فى ضبط الغضب فى المرحلة الابتدائية .

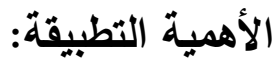
1-الاستفادة من نتائج الدراسة الحالية بالتعرف على فعالية برنامج إرشادى باللعب لضبط

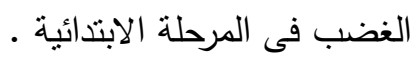

r-يمكن أن تساعد هذه الدراسة المختصين في مجال التربية وعلم النفس علي إعداد الخطط

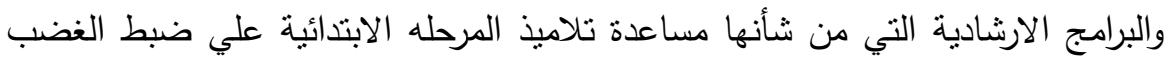


r-النتائج التي سوف يتم التوصل إليها بمكن ان تثير وعي الباحثين بإهميه الالتفات لهذه

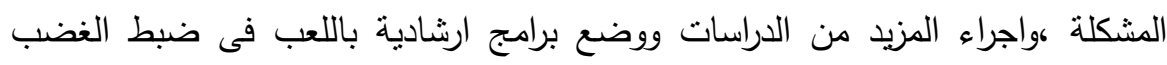
خاصة فى المرحلة الابتدائية الاكثر عرضه للمشكلات الانفعالية والسلوكية

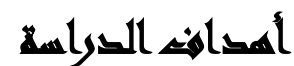

1-معرفة ماأذا كان البرنامج الارشادى باللعب يؤدى إلى ضبط الغضب لدى عينة من أطفال المرحلة الابتدائية

r- إعداد مقياس للغضب لدى المرحلة الابتدائية .

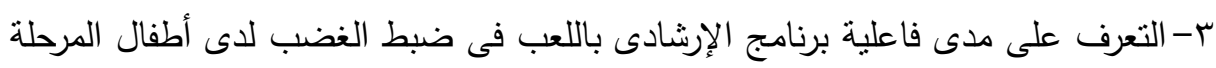

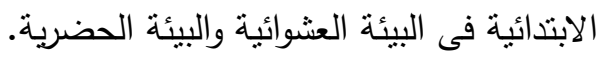

\section{هزوضر التواسم}

1-يوجد فرق دال إحصائيا بين متوسطى رتب درجات المجموعتين الضابطة والتجريبية لدى أطفال المرحلة الابتدائية فى النطبيق البعدى لمقياس الغضب لئب لصالح المجموعة التجريبية

$$
\text { للبيئة العشوائية. }
$$

ץ-يوجد فرق دال إحصائيا بين متوسطى رثب درجات المجموعتين الضابطة والتجريبية لدى أطفال المرحلة الابندائية فى النطبيق البعدى لمقياس الغضب لئب لصالح المجموعة التجريبية

$$
\text { للبيئة الحضرية. }
$$

r-توجد فرق دال احصائيا بين منوسطى رثب درجات المجموعة التجريبية لدى أطفال المرحلة الابتدائية فى التطبيقين القبلى والبعدى لمقياس الغضب بلى بعد تطبيق البرنامج

$$
\text { لصالح التطبيق البعدى للبيئة العشوائية. }
$$

ع-توجد فرق دال احصائيا بين متوسطى رتب درجات المجموعة التجريبية لاى أطفال المرحلة الابندائية فى التطبيقين القبلى والبعدى لمقياس الغضب دئب بعد تطبيق البرنامج

$$
\text { لصالح التطبيق البعدى للبيئة الحضرية. }
$$

ه- لا توجد فرق دال احصائيا بين منوسطى رثب درجات المجموعة التجريبية لدى أطفال المرحلة الابتدائية فى النطبيقين البعدى و التتبعى لمقياس الغضب للبئ للبيئة العشوائية.

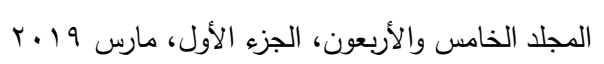


צ- لا توجد فرق دال احصائيا بين متوسطى رثب درجات المجموعة التجريبية لاى أطفال

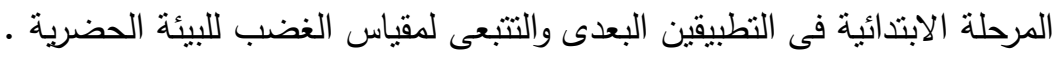

\section{همطللحايت الصراسة}

تتحدد مصطلحات الدراسة الحالية فى إربع مصطلحات أساسية يمكن تعريفها إجرائيا

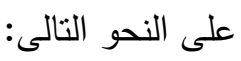

ا. البرنامج الإرشادى باللعب: Play Counseling Program: هو برنامج مطور ومخطط بناء على استرايتجيات متكاملة لتقديم الخدمات الإرشادية المباشرة وغير

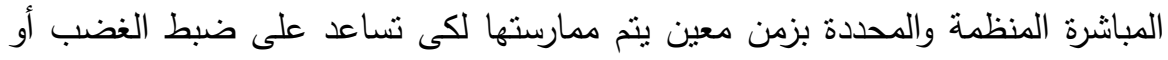
التحكم فيه، وهى تخدم جميع جوانب الثخصية المعرفية والوجدانية و السلوكية، وتستتد

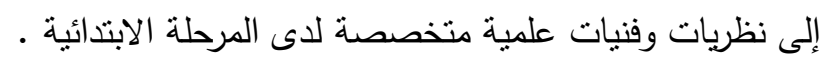

r. اللعب: Play: يتجسد ذلك فى برنامج اللعب الذى يحتوى على الأنشطة الفنية والألعاب

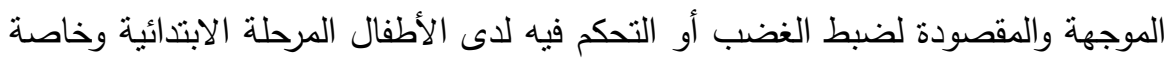
المرحلة المتأخرة بحيث تتتاسب تلك الأنشطة والألعاب مع طبيعة الجسمية والعقلية

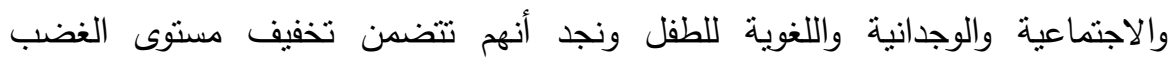
والمشكلات الاففعالية لاعى المرحلة الابتدائية r. الغضب: Anger: الغضب هو حالة انفعالية تشتمل على عدة مستويات، تبدأ بالغضب البسيط كالغضب والاستثارة والضيق ثم تتنهى بالغضب الثنديد المتمثل بالتمزيق والتثمير

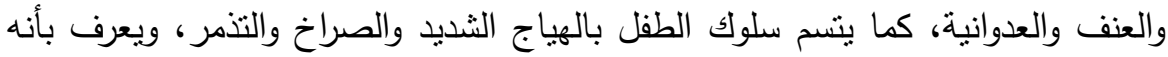
الدرجة التى يحصل عيلها المفحوص على المقياس الذى تم اعتماده فى هذه الدراسة . ع. المرحلة الابتدائية: Primary Stage: وهى المرحلة التى تتراوح عمر الأطفال فيها من | 1-r (، وهم التلاميذ الذن سوف يخضعون للدراسة فى محافظة الاسماعيلية، ومن

$$
\text { الصفوف العليا ( الخامس والسادس الابتدائى ) }
$$




\section{=راسايت ساريخ}

يمكن أن نعرض الدراسات السابقة عبر محاور التالية:

المحور الأول : دراسات تتاولت برامج اللعب فى خفض المشكلات السلوكية والانفعالية ا. دراسة: باول ل. تيجس ( Tigge\&Paul 2010): هدفت الدراسة إلى التحقق من العلاج باللعب للاطفال الأمريكيين من أصل افريقى الذين تقع أعمارهم بمرحلة المدرسة الابتدائية والمشخصين باضطراب التحدى المعارض كتثرر عندما تم تطبيق فنيات العلاج باللعب أكثر من سنة دراسية؛ ان كل طفل فى التجرية أظهر سلوكيات خلل أقل وانخفضت

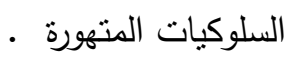

r. دراسة: حنان مبارك محمد القحطانى(1 1 × r): تهـف الدراسة الحالية إلى فعالية برنامج

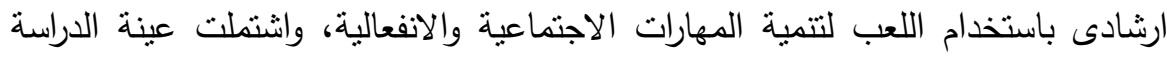
على r من المعلمات و • ( أطفال ضعاف السمع، يتراوح عمرهم الزمنى (ع-7) ولديهم

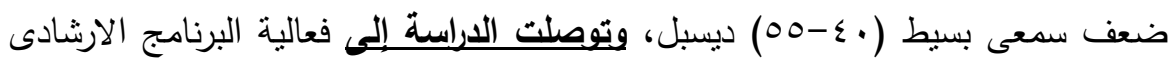

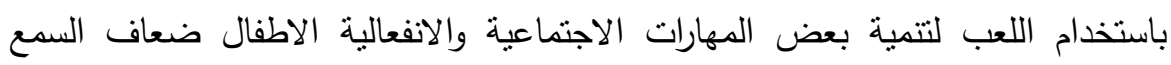

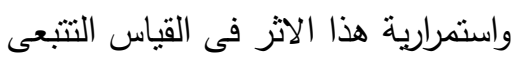

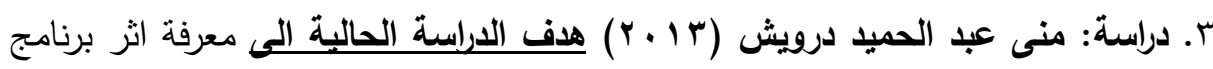
ارشادى باللعب فى خفض حدة الأضطرابات السلوكية (السلوك العدوانى - السلوك

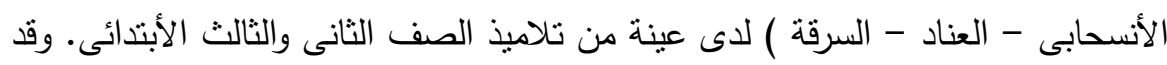

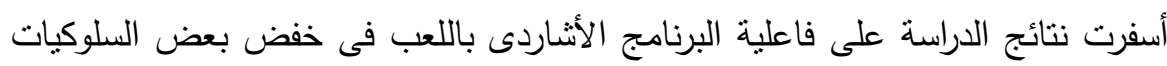

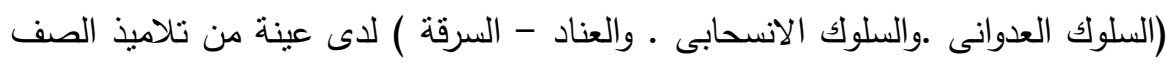

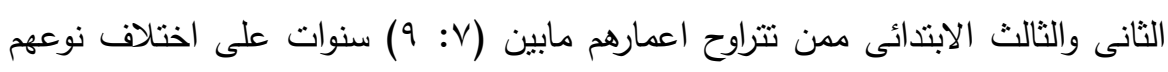

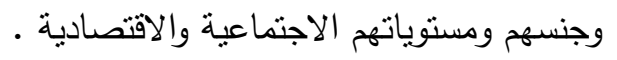
ع. درسة: براتون واو جيامبو ( Bratton \& Ojiambo,2014) هدفت إلىى التعرف على أثر مجموعة أنشطة باللعب فى حل المشكلات لدى عينة من الأطفال الايتام بإوغندا

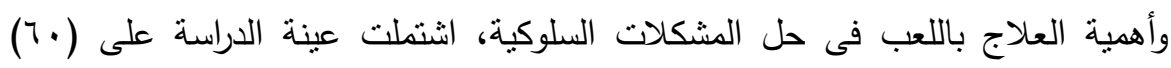

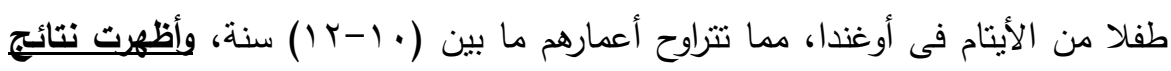
208

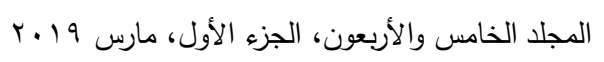


اللاراسة انخفاض كبير فى المشكلات السلوكية نتيجة استخدام اللعب خاصة للأطفال المجموعة التجريبية التى خضعت إلى الدراسة العلاج باللعب بالمقارنة بالمجموعة الضابطة التى لم تتلق إى تدريب المحور الثانى: دراسات تتاولت برامج فى ضبط أو خفض الغضب

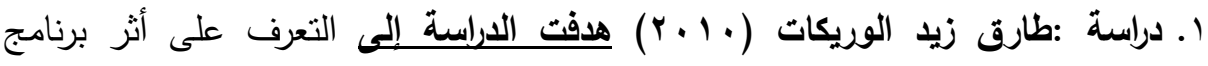
ارشادى فى ضبط الغضب وتتمية الاهتمام الاجتماعى وخفض الاكتئاب لاى الاحداث

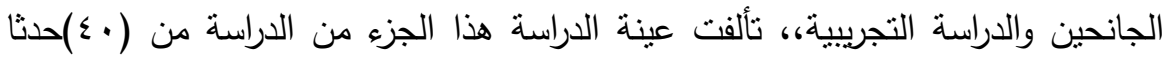
جانحا،.وأسفرت تنائج تحليل وجود فروق دالة إحصائيا عند مستوى الدلالة (0., •) بين المجموعة التجريبية والمجموعة الضابطة، فى مستوى القدرة على ضبط الغضب، والاهتمام الاجتماعى، ودرجة الاكتئاب لدى الاحداث الجانحين، تعزى البرنامج الارشادى لصالح

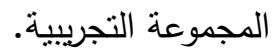

r. دراسة: بورى بياجود (Bidgood, Burce A : et al 2010) هدفت الدراسة إلى تقييم برنامج لدعم النواحى المزاجية والانفعالية (STEAM) لأطفال المرحلة الأساسية

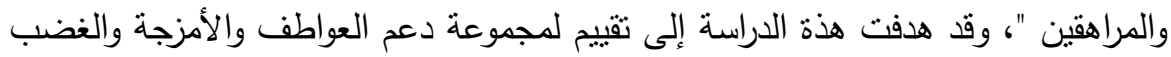

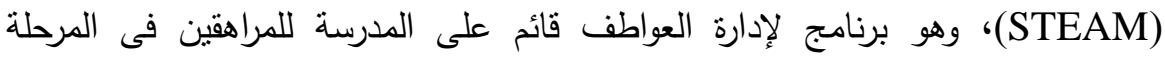
الابتدائية ـ وتثثير النتائج إلى أهمية التدخل المبكر للمساعدة الأطفال فى تطوير التحكم

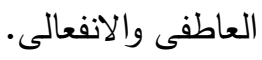
r. دراسة: زهاو وآخرون ( Zhou et .al 2010 ( هدفت الدراسة إلى التعرف على العلاقة بين الضبط المزاجى والغضب على كل من التحصيل الاكاديمى والتكيف الاجتماعى عند

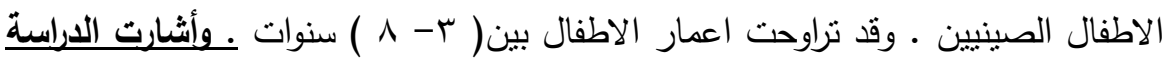

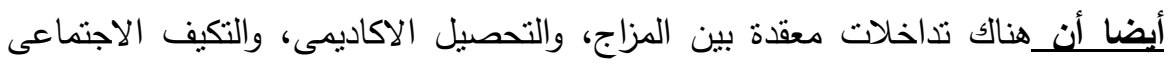
لاى أطفال مرحلة الدراسة ع. دراسة أوز وايسان (oz\&Aysan 2011) هدفت الاراسة إلى الكثف عن أثر التدريب على استراتيجيات التعامل مع الغضب ومهارات التواصل لدى المراهقين ـ تكونت عينة 
الدراسة من ( • 7) طالبا تراوحت أعمارهم بين (10-7 (1) سنة ـ وقد أظهرت نتائج الدراسة وجود فروق ذات دلالة إحصائية فى خفض حالة الغضب لصالح المجموعة التجريبية

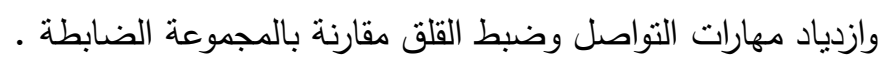

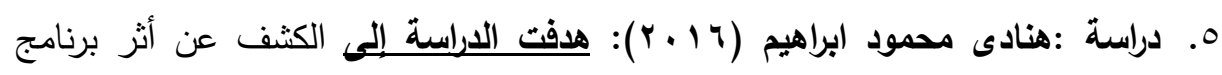

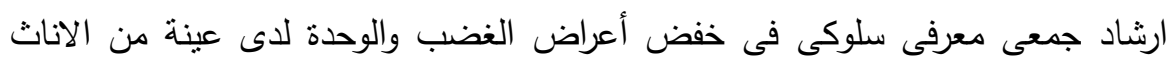

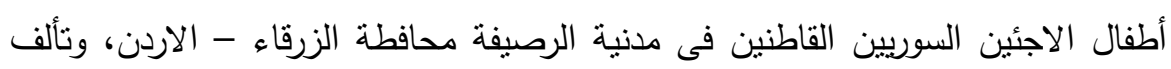

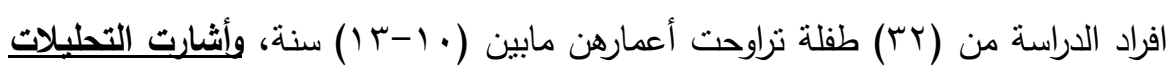

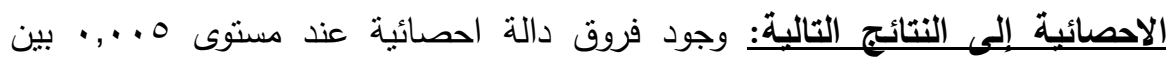

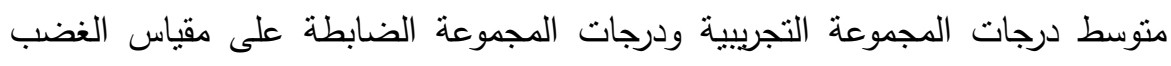
بأبعاده الستة فى القياس البعدى لصالح المجموعة التجريبية مما يشير إلى كفاءه البرنامج

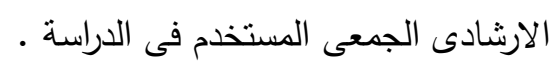

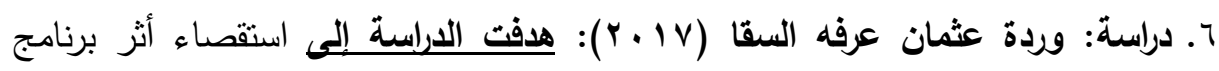

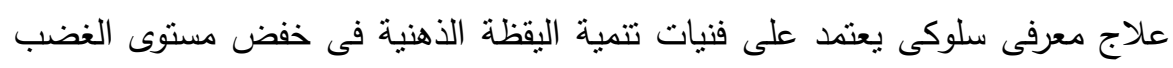

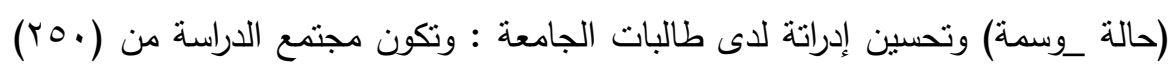

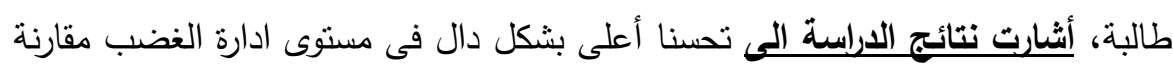

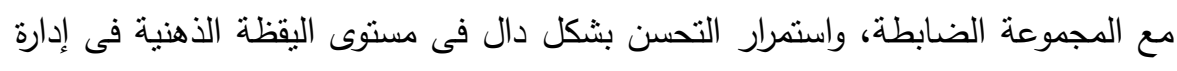
الغضب فى القياس التتبعى.

المحور الثالث: دراسات تتاولت اللعب فى خفض أو ضبط الغضب

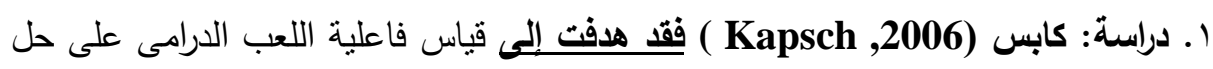

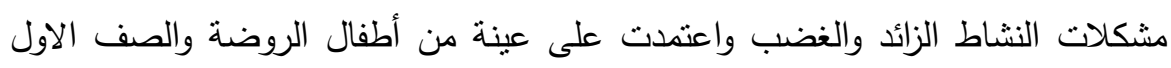

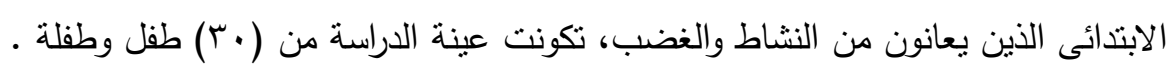
وأثارت النتائج عن وجود فروق دالة إحصائيا لصالح المجموعة التجريبية وذلك فاعلية اللعب الدرامى على حل مشكلات النشاط الزائد والغضب حيث انخفض حدة النشاط الزائد والغضب لدى أطفال الروضة والصف حل ملنات الاول الابندائى. 


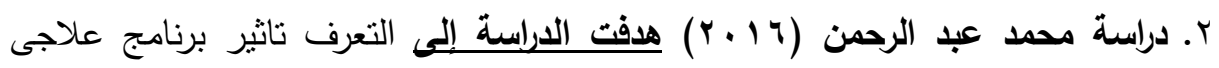
باللعب فى خفض بعض الاضطرابات السلوكية لدى الطفل التوحدى، وذللك بدولة الامارات

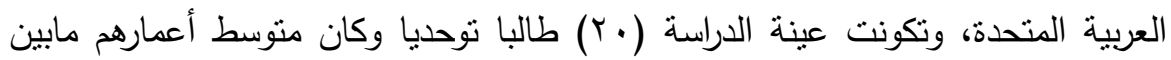

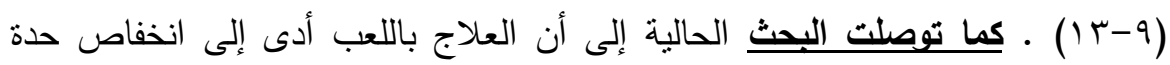
السلوك العدوانى لدى الاطفال التوحيديين التعبير عن الغضب وعدم إلى إيذاء الذات .

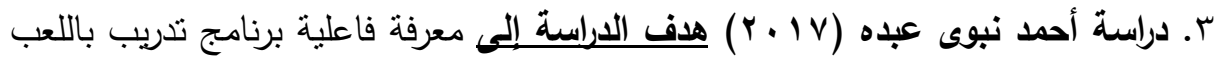
فى تخفيف اضطرابات العناد والمتحدى لاى مجموعتين من التلاميذ الصم وذوى الاعاقة

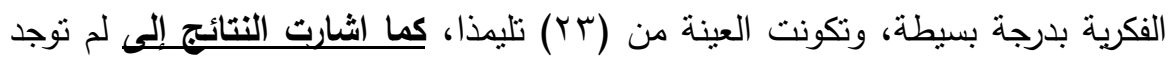

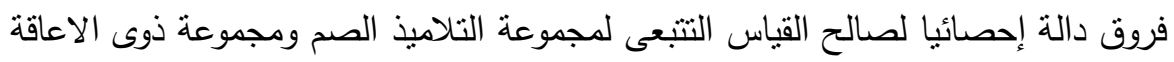

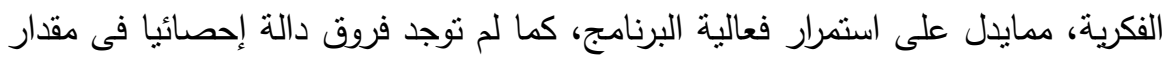
تحسن تلاميذ كل مجموعة من المجموعتين عن اخرى الحئه

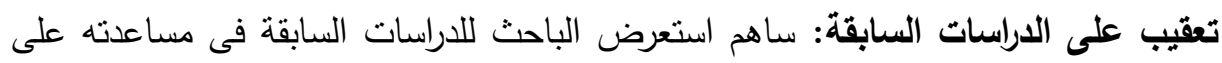
تحديد النقطة التى سيبدأ منها فى البرنامج الحالى للاراسة.

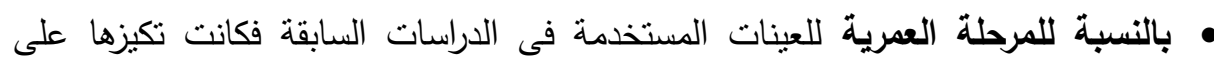

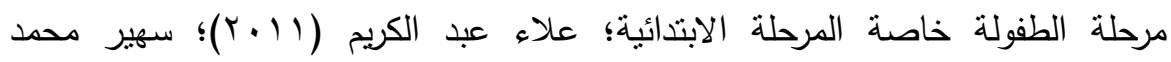

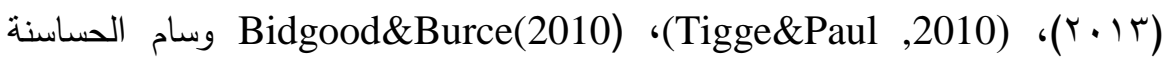

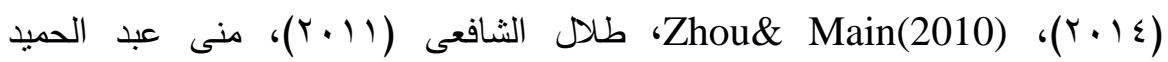

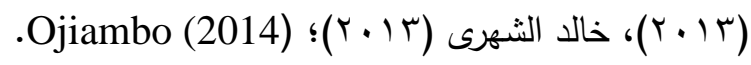

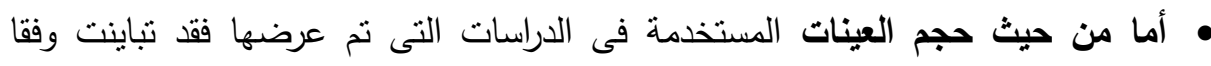
لأهداف الدراسة ما بين العينات الصغيرة والكبيرة التى اعتمد عيلها فى الدراسات التجريبية

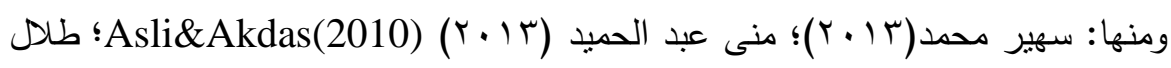

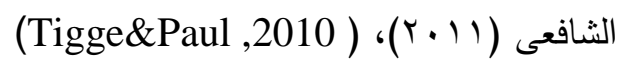
• أما من حيث النتائج قد تتوعت الاهداف التى نسعى إليها كل دراسة من الدراسات

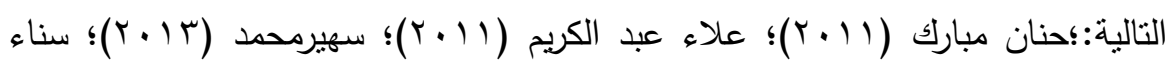

$$
\text { المجلد الخامس والأربعون، الجزء الأول، مارس } 19
$$




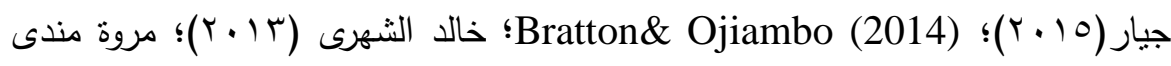

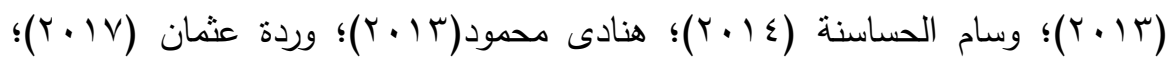
OAsli\& Akdas(2010)

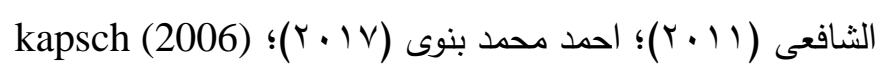
كثنت العديد من الدراسات أن اللعب يؤدى إلى خفض المشكلات السلوكية لدى المرحلة

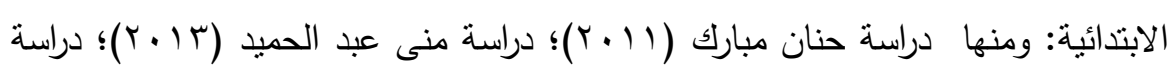

. (Tigge\&Paul 2010) .Bratton\& Ojiambo (2014) • كا كثفت العديد من الدراسات أن البرامج الارشادية ضبط الغضب أو لخفض الغضب.

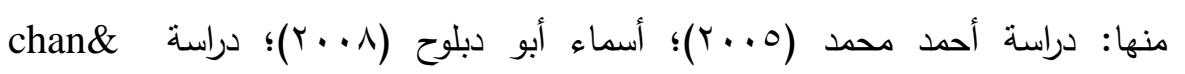

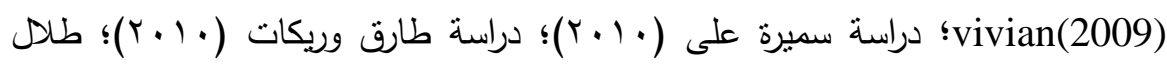

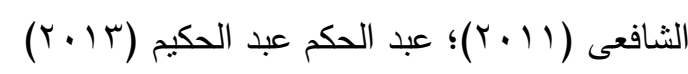
• كما كثفت بعض الدراسات على أن فعالية اللعب خفض العدوان أوالقلق أو أو الغضب . منها؛ دراسة Kapsch(2006 فعالية اللعب الدامى فى حلى المشكلات النعات النشاط الزائد والغضب؛ أحمد نبوى (Y. V V) فاعلية تدريب باللعب فى تخفيف سلوكيات الغضب،

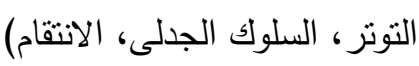

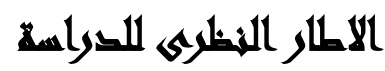

Encarta World English مفهوم اللعب: يقدم قاموس إنكراتا الانجليزى العالمى Dictionary 1999 معانى كثيرة لكلمة Play منها : ينخرط فى نشاط ممتع بغرض التسلية، يفعل شيئا ما بغرض المرح وليس الجد، ويكثف ذلك عن طريقه وظيفية فى تتاول اللعب من

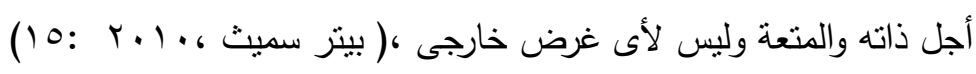

مفهوم الغضب: تعريف قاموس اكسفورد (Oxford dictiOnry) : الغضب عبارة عن

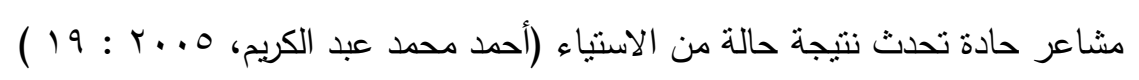




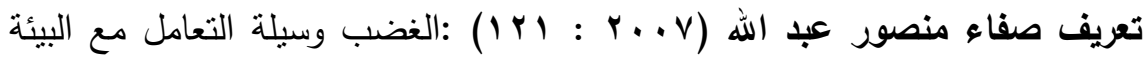
المهددة، ويتضمن استجابات طارئة وسلوكا مضادا المثيرات التهديد، ويصاحبه تغيرات فسيولوجية لإعداد الفرد لسلوك يناسب الموقف المهدد يعريف الباحثون للغضب: الغضب هو أنفعال يصدر من الفرد حين التعرض لمواقف

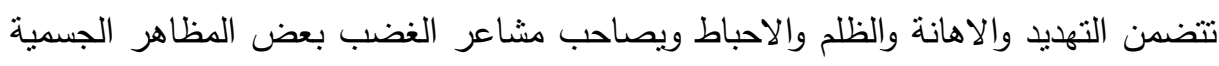
والنفسية ويتم التعبير عنه بطريقة لفظية وبدنية ـ ولعدم إثباع حاجاته فيقوم بتوجيه غضبه للخارج قاصدا منه إظهار مشاعره فى صورة عدوانى لفظى أو غير اللفظى ولئه النظريات المفسرة للعب: • نظرية التحليل النفسى واللعب: يرى فرويد أن العب وسيلة لتحقيق أمنيات الأطفال وكنلك

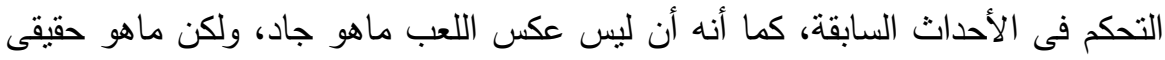
كما أن الأطفال يذكرون كل شئ مما قد ترك ليهم أنطباعا قويا فى حياتهم الواقعية وهم بذلك يتحرون من قوة الانطباع ويجعلون أنفسهم السيطرون على الموقف ( رشا السيد،

$$
\text { ( } r \cdot: \text { : } \cdot 9
$$

• النظرية التفيسية: ترى مدرسة التحليل النفسى التى نادى بها فرويد أن اللعب يساعد على التى

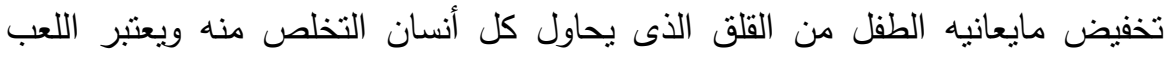

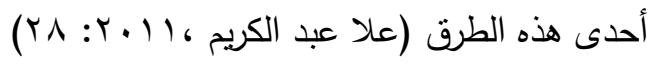
النظريات المفسره للغضب • النظرية التحليل النفسى: ترجع هذه النظرية إلى سيجموند فرويد الذى يؤكد طبقا أن الغضب والعدوان ينبعان من دافع أساسى عند الإنسان، وهو غريزة التى تقود فى النهاية

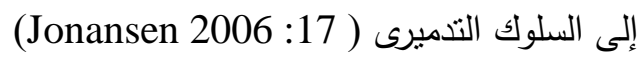
•النظرية السلوكية: تنير النظرية السلوكية إلى أن الغضب شأنه شأن أى سلوك يتم تعلمه

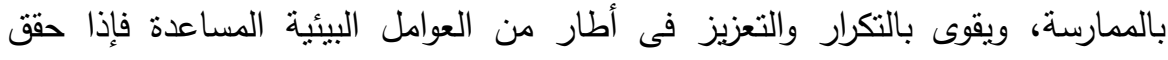
الغضب وثورته الوصول إلى المطلوب وتحقيق الأهداف المرجوة منه فإن منل هذه

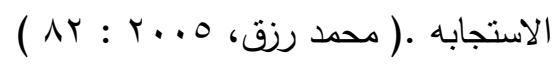

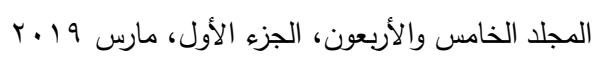




\section{الاجبراءايت المنهجية للصواسمة}

منهج الاراسة: نعتمد الدراسة الحالية على المنهج التجريبى باعتبارها تجرية هدفها التعرف على فعالية برنامج إرشادى لضبط الغضب لدى أطفال المرحلة الابتدائية

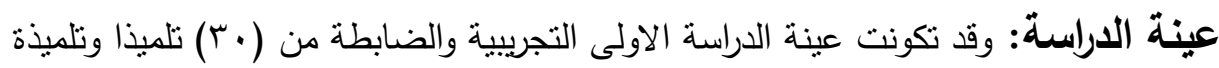

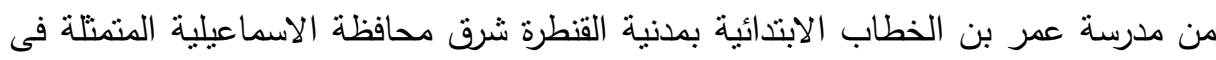

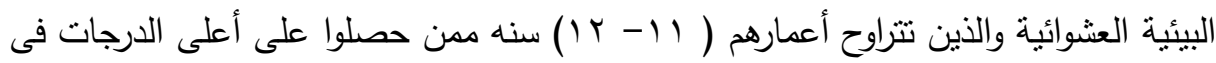
مقياس الدراسة قام الباحث بتقسيم العينة إلى مجموعتين منساويتنين الاولى مجموعة التجريبية (10) تلميذا وخضعت للبرنامج الارشادى باللعب لدى أطفال المرحلة الابتدائية والثانية مجموعة الضابطة (10) تلميذا لم تخضع للبرنامج الارشادى، كما تكونت عينة الدراسة الثانية التجريبية والضابطة من ( Tr) تلميذا وتلميذة من مدرسة عباس العقاد الابتدائية بمحافظة

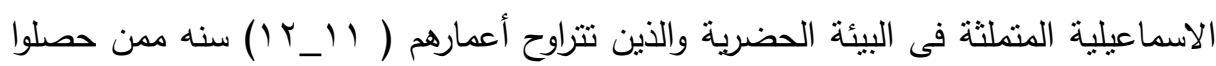
أعلى مقياس الدراسة قام الباحث بتقسيم العينة إلى مجموعتين متساويتين الاولى مجموعة لبنه التجريبية (r) تلميذا وخضعت للبرنامج الارشادى باللعب لدى أطفال المرحلة الابتدائية

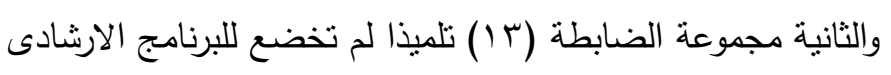

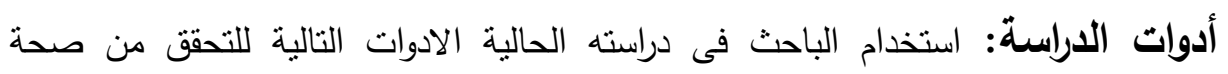
فروض الاراسة:

• مقياس الغضب للاطفال المرحلة الابتدائية ويتكون من خمسة ابعاد هما (الغضب الداخلى - الغضب الخارجى - مثيرات الغضب - نكرار الغضب مداه - الاعراض النفسيجسية )

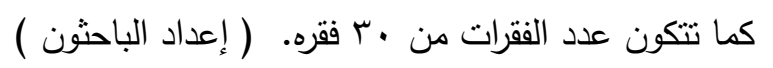

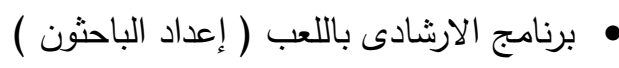

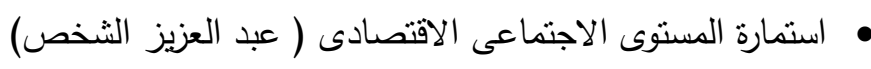
صدق المقياس: قامت الباحث بتقتين فقرات المقياس، وذلك للتاكد من صدقها على النحو التالى 
- صدق المحكمين: عرض الباحث المقياس على مجموعة من الخبراء فى مجال الاختصاص، للتعرف على مدى ملائمة المقياس لما وضع من أجله، ولقد ابدوا الملاحظات

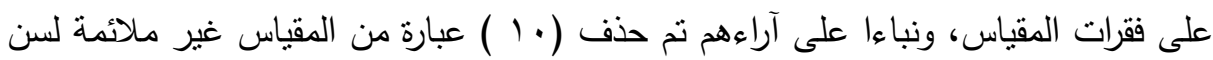

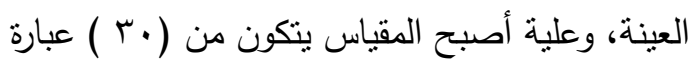
الأساليب الاحصائية المستخدمة فى الاراسة تم استخدام البرنامج الاحصائي Spss) Stochastic Package For Social Science لتحليل البيانات ومعالجتها 1- 1- معامل الارتباط لبيرسون بlpha - Cronbach Spearman - r-معامل الثبات بطريقة التجرئة النفصية لـ سييرمان - براون Brown

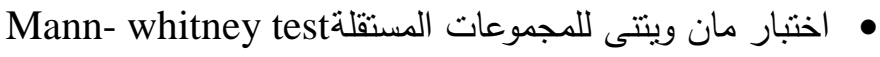
• • اختبار ويلكوكسون للمجموعات المرنبطة wilcoxon Test

$$
\text { البرنامج الإرشادى باللعب ( إعداد الباحثون ) }
$$

التعريف الإجرائى للبرنامج: ويعرف الباحث البرنامج فى هذه الدراسة بأنه مجموعة من الإن البهن

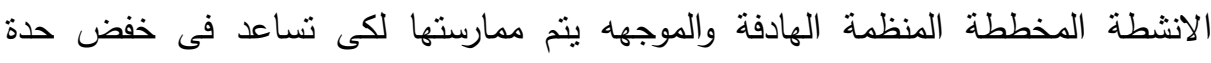
الغضب عند الأطفال المرحلة الابتدائية، وهى تخدم جميع جوانب الثخصية المعرفية والوجدانية والسلوكية، وتستتد إلى نظريات وفنيات علمية متخصصة

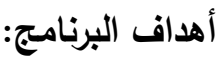

اللهف العام لللبرنامج: هو خفض حدة الغضب لدى عينة من الاطفال من تلاميذ الصفين الخامس والسادس من المرحلة الابتدائية .

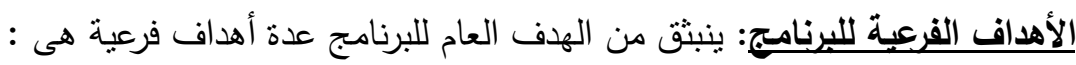

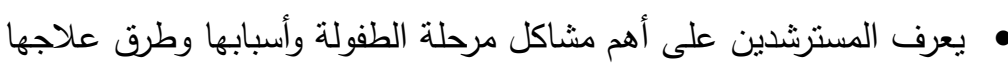
• تعرف المسترشدين على جوانب التوافق النفسى ومدى مساهمته فى تحقيق الصحة النفسية

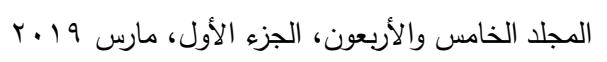




$$
\begin{aligned}
& \text { تدريب الاطفال على كيفية التعامل مع غضبهم } \\
& \text { • عمل نتفيس انفعالى للتلاميذ } \\
& \text { استثمار طاقات التلاميذ فى أنشطة وألعاب مفيدة }
\end{aligned}
$$

\begin{tabular}{|c|c|c|c|}
\hline فنيات وأنشطة الجلسة & هدف الجلسة & عنوان الجلسة & الجلمثة \\
\hline المناقثة والحوار & تعارف بين أعضاء البينه وبوعة بعضهمج & تعرف بين أعضاء لمجموعة & 1 \\
\hline المناقشة والحوار & يناقش للاطفال العادات السلوكية الغضب & اكتساب عن الغضب سلوكية & $r$ \\
\hline 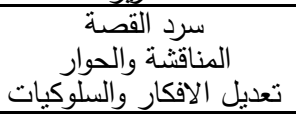 & وعوض البها والسلوكيات الصحيح الانفعالية الخاطئة & نشاط قصصى فكر وعبر & r \\
\hline أنشطة ألعاب حركية & يتعلم الاطفال ألعاب جديدة تساعد فى التوتي & التى تخفضة الانشطة من الغضدنبة & $\varepsilon$ \\
\hline لعنب الدور والتمثيلن & الانفعالات بطريقة الصيقيحة من التعبير غلال & ل لعب الدور & 0 \\
\hline والمناقشة والنلوين & 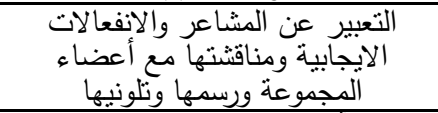 & ارسم ولون & 7 \\
\hline المناقشة والحوأرة ،رالتعزيز & تدريب أعضلت والتوتر الانجموعالت علي خفضية & لعبة المتاهة & $\checkmark$ \\
\hline تعناقثنة والإكوار & تعريف التلاميذ كيفية التعبيرة عن ايجابية & البحث عن الكنز & $\wedge$ \\
\hline المناقشتة الحوار & يكتسب التلاميذ مهارات الاسترخاء فى غض التهر & لعبة الاسترخاء & 9 \\
\hline الالصاب؛ & تدريب الاطفات بشكل طريقة الحديث مع & لعبة السلحفاء & 1. \\
\hline المناقثة والحوار ،التعزيز & عمل تنفيس انفعالى ألعاب حركية & ألعاب جماعية حركية & 11 \\
\hline التناقشة والحوار & تمكين الطفل التعبير عن الغضبة & خلالّ الرسم والكتابة من & ir \\
\hline المناقثة والحوار & تدريب الاطفال زبادة الثقة بالنفس ورفع الانشطة & لعبة شد الحبل & 1r \\
\hline التعناقشة والحوار & التعبير عن الغضبب بالسلوكيات الإبية & بالونات الغضب & $1 \varepsilon$ \\
\hline المناقشة والحوار & تدريب الاطفال على تحقيق التفريغ الاستبـي & اللعب التخليى & 10 \\
\hline المناقثة والحوار ،التعزيز & تدريب الاطفال على الصدق فى الحديث & لعبة كرسى الاعتراف & 17 \\
\hline تبادل الادوار & عرض السلوكيات والانفعالات الخاطئة والسيح & مشاهدة فيلم كرنونى & IV \\
\hline المناقثنة والحوار & 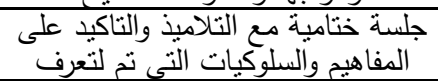 & الجلسة الختامية & 11 \\
\hline
\end{tabular}

جدول رقم (1): جدول المجمع لجلسات وأنشطة البرنامج الارشادى باللعب 
أهمية البرنامج: يقدم البرنامج مجموعة من الأنشطة والألعاب المتتوعة التى يمكن أن يقتى

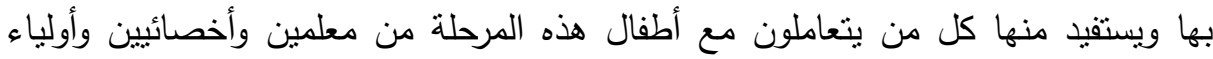
أمور وتساعدهم على حل مشكلاتهم الانفعالية والسلوكية والتقرب منهم وفهمه أكثر .

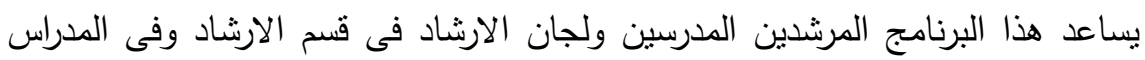

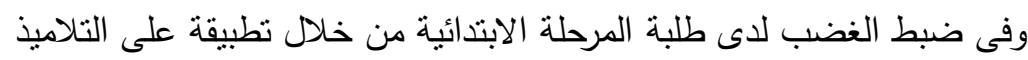
الأسس التى يقوم عيلها البرنامج الارشادى:

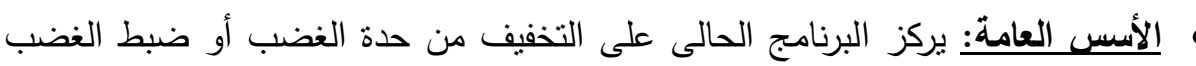

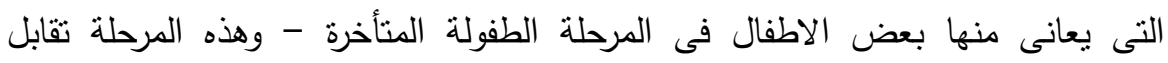
الصفوف الخامس والسادس من المرحلة الابتدائية

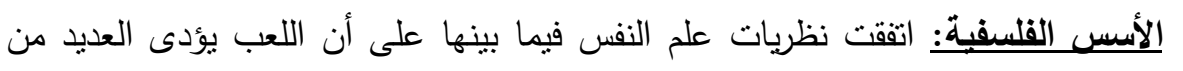
الوظائف عند الطفل، فهو وسيلة يتخلض الطفل عن طريقها من التوتز الانفعالى والقلق والكبت، ووسيلة لتصريف واستثمار الطاقة الزائدة واكتشاف الامكانات والقدرات ن كما يتيح للطفل الفرصة لتعلم القيم والاخلاقيات وطرق التفكير والسلوكيات السوية بطريقة ممتعة وسلسة .واللعب دور فى التقليل من مشطلات التوافق الانفعالى والاجتماعى لاى الاطفال

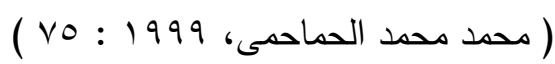

•الأسس الاجتماعية: يتيح اللعب مناخ جيد من الناحية التربوية آمن ومريح يسهل عملية التعلم وتعديل السلوكيات المضطربة عند الاطفال، فاللعب فى وسط مجموعة يجعل الطفل

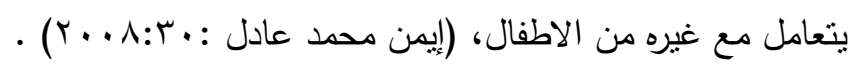

الأساليب المتبعة فى البرنامج الارشادى: سينتهج البرنامج بصورة مبدئية خلال تطبيقة على لئ عينة الدراسة عدة أساليب منه أسلوب المحاضرات والمناقتشات:، ألعاب نرفيهية إبداعية ورياضية، النعزيز، النمذجة، تعديل الافكار ، الاسترخاء الهابه

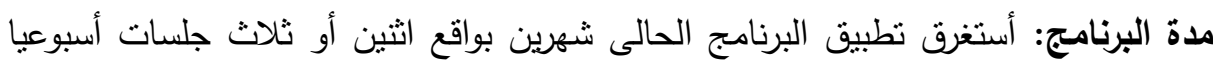

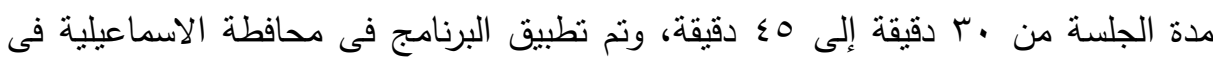

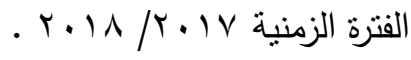

$$
\text { المجلد الخامس والأربعون، الجزء الأول، مارس } 19
$$




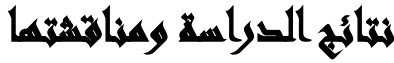

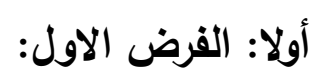

جدول رقم (ץ): نتائج "اختبار مان ويتتى"لايجاد فرق دال إحصائيا بين متوسطى رتب درجات

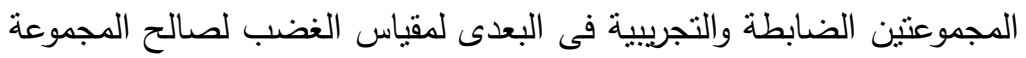

التجريبية (للبيئة العشوائية)

\begin{tabular}{|c|c|c|c|c|c|c|c|c|}
\hline الدلالة & $\mathbf{W}$ & $\mathbf{Z}$ & $\mathbf{U}$ & مجموع الرتب & متوبط الرتب & ن & المجموعات & الابعاد \\
\hline \multirow{2}{*}{ 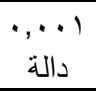 } & \multirow{2}{*}{ 10r } & \multirow{2}{*}{$r, r \leq$} & \multirow{2}{*}{ זי } & 104 & $1 \cdot, r$. & 10 & التجريبية|العشوائية & \multirow{2}{*}{ مثيرات } \\
\hline & & & & MIr & $r \cdot, \Lambda$. & 10 & الضابطة|لعشوائية & \\
\hline \multirow{2}{*}{ 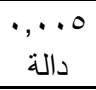 } & \multirow{2}{*}{177} & \multirow{2}{*}{$r, \wedge)$} & \multirow{2}{*}{$\leq 7$} & 177 & $11, \cdot V$ & 10 & التجريبية|العشوائية & \multirow{2}{*}{ الذضبل } \\
\hline & & & & $r 99$ & 19,94 & 10 & الضابطة|العشوائية & \\
\hline \multirow{2}{*}{ 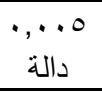 } & \multirow{2}{*}{170} & \multirow{2}{*}{$r, \wedge}$. & \multirow{2}{*}{$\leq V$} & 170 & $11, \mathrm{~V}$ & 10 & التجريبية|لعشوائية & \multirow{2}{*}{ الخارجى الغضب } \\
\hline & & & & 199 & $19,9$. & 10 & الضابطة العشوائبة & \\
\hline \multirow{2}{*}{ 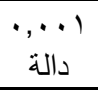 } & \multirow{2}{*}{100} & \multirow{2}{*}{$r, r \wedge$} & \multirow{2}{*}{ ro } & 100 & 1.,TH & 10 & التجريبية|العشوائية & \multirow{2}{*}{ ومداهوتكراره } \\
\hline & & & & M. & $r \cdot, T V$ & 10 & الضابطة العشوائبة & \\
\hline \multirow{2}{*}{ 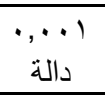 } & \multirow{2}{*}{100} & \multirow{2}{*}{ r, rA } & \multirow{2}{*}{ ro } & 100 & 1., & 10 & التجريبية|العشوائية & \multirow{2}{*}{ الالفسيجمية } \\
\hline & & & & M. & $r \cdot, T V$ & 10 & الضابطة العشوائبة & \\
\hline \multirow{2}{*}{ دالة } & \multirow{2}{*}{ rri } & \multirow{2}{*}{$\varepsilon, 11$} & $1 \pi$ & $1 \pi r, 0$. & $\wedge, q$. & 10 & التجريبية|لعشوائية & \multirow{2}{*}{ الدرجة الكلية } \\
\hline & & & 0. & . & $r, 1$. & 10 & الضابطة العشوائية & \\
\hline
\end{tabular}

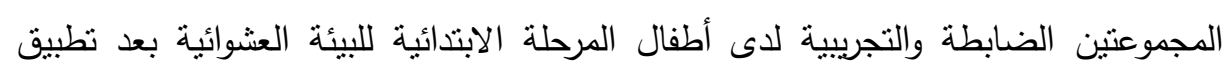

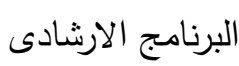




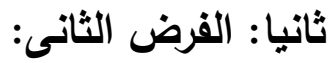
جدول رقم (ץ): تتائج "اختبار مان ويتنى"لايجاد فرق دال إحصائيا بين متوسطى رثب درجات المجموعنين الضابطة والتجريبيةفى التطبيق البعدى لمقياس الغضب لصالح

المجموعة التجربيية بيئة الحضرية

\begin{tabular}{|c|c|c|c|c|c|c|c|c|}
\hline الدالة & $\mathbf{W}$ & $\mathbf{Z}$ & $\mathbf{U}$ & مجموع & متوسط & ن & المجموعات & الابعاد \\
\hline \multirow{2}{*}{ دالة., } & \multirow{2}{*}{110} & \multirow{2}{*}{$r, \vee \wedge$} & \multirow{2}{*}{ r } & 110 & $\Lambda, \wedge \wedge$ & $1 \pi$ & التجريبية|الحضرية & \multirow{2}{*}{ مثيرات } \\
\hline & & & & TrO & $1 \Lambda, 1 Y$ & 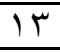 & الضابطة|الحضرية & \\
\hline \multirow{2}{*}{ دالة", } & \multirow{2}{*}{119} & \multirow{2}{*}{$r, q}$. & \multirow{2}{*}{ rᄉ } & 119 & 9,19 & $1 \pi$ & التجريبية|الحضرية & \multirow{2}{*}{ الغضلب } \\
\hline & & & & TMT & $|V, \Lambda|$ & $\pi$ & الضابطة|الحضرية & \\
\hline \multirow{2}{*}{ 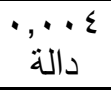 } & \multirow{2}{*}{ Kr. } & \multirow{2}{*}{$r, v q$} & \multirow{2}{*}{ TV } & $\pi$. & $9, Y$ & $\pi$ & التجريبية|الحضرية & \multirow{2}{*}{ الخضارجي } \\
\hline & & & & זT. & $I V, \wedge$. & 14 & الضابطة|الحضرية & \\
\hline \multirow{2}{*}{ 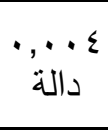 } & \multirow[b]{2}{*}{$M$} & \multirow[b]{2}{*}{ r,VA } & \multirow[b]{2}{*}{$r \cdot$} & $1 \pi 1$ & $9, r_{0}$ & $1 \pi$ & التجريبية|الحضرية & \multirow{2}{*}{ والغضب } \\
\hline & & & & KYq & $1 V, 70$ & 14 & الضابطة|الحضرية & \\
\hline \multirow{2}{*}{ 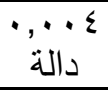 } & \multirow{2}{*}{$|r|$} & \multirow{2}{*}{$r, \vee \wedge$} & \multirow{2}{*}{$r}$. & $|r|$ & $9, r_{0}$ & $1 \pi$ & التجريبية|الحضرية & \multirow{2}{*}{ النفسيجمية } \\
\hline & & & & rYq & $1 V, 70$ & $\pi$ & الضابطة|الحضرية & \\
\hline \multirow{2}{*}{ 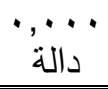 } & \multirow{2}{*}{$1 \cdot 1$} & \multirow{2}{*}{$r, \varepsilon \vee$} & \multirow{2}{*}{ iV } & $1 \cdot 1$ & $\Lambda, \Gamma_{1}$ & $1 \pi$ & التجريبية|الحضرية & \multirow{2}{*}{ الكلية الكرجة } \\
\hline & & & & $r \leq r$ & 11,79 & $1 \Gamma$ & الضابطة|الحضرية & \\
\hline
\end{tabular}

ويتضح من الجدول السابق: وجود فرق دال إحصائيا بين منوسطى رتب درجات الهجموعنين الضابطة والتجريبية لدى أطفال المرحلة الابتدائية للبيئة الحضرية بعد تطبيق

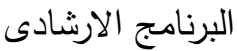

ثالثا: مناقثة الفرض الاولى والثانى: يوجد فروق دالة إحصائيا بين منوسطى رثب درجات المجموعتين الضابطة والتجريبية لاى أطفال المرحلة الابتدائية فى التطبيق البعدى لهى لهري لمقياس الغضب لصالح المجموعة التجريبية فى البيئتن العشوائية والحضرية. وقد أثنارت نتائج اختبار مان - ويتتى Mann- Whitney Test لحساب الفرق بين منوسطى رثب الدرجات المستقلة، إلى أن هناك فروق ذات دالة احصائية بين أفراد المجموعة التجريبية (بيئية العشوائية وحضرية ) وأفراد المجموعة الضابطة (بيئة العشوائية والحضرية )

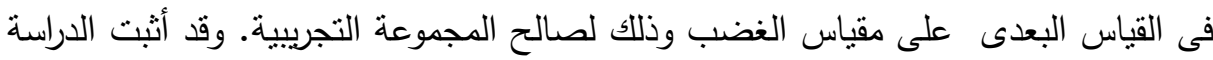

$$
\text { المجلد الخامس والأربعون، الجزء الأول، مارس } 9 \text { ب. }
$$


الحالية صحة هذا الفرض حيث أدى فعالية برنامج الارشادى باللعب مع أطفال المرحلة

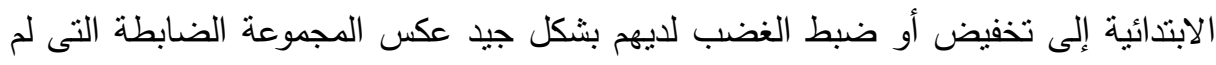
تتعرض لأى تدريب.

حيث أكد الدراسات السابقة على أهمية اللعب فى خفض المشكلات السلوكية والانفعالية

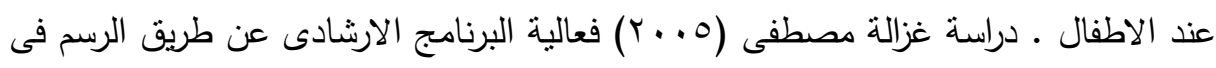

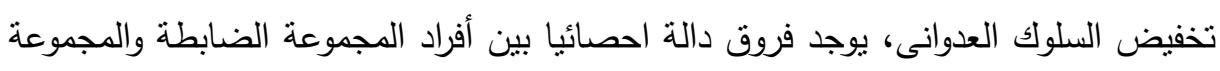

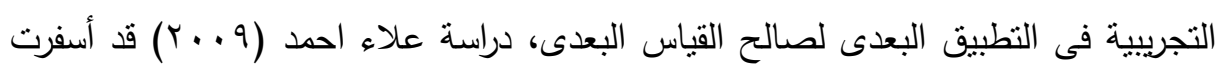

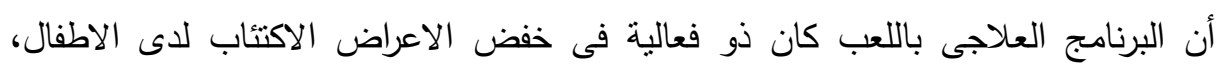

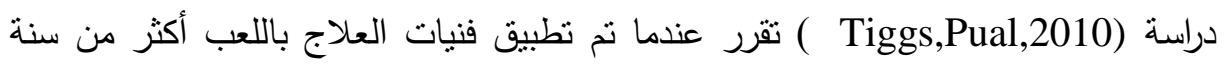

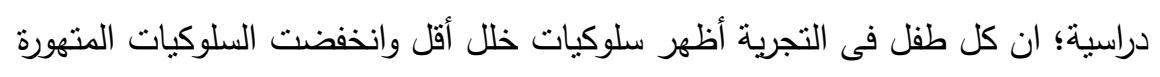

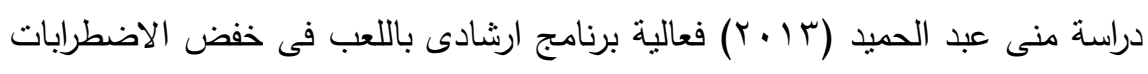

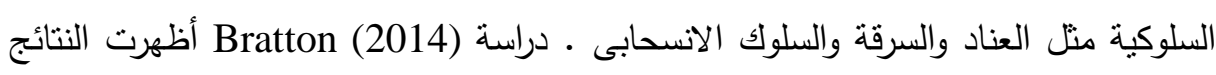

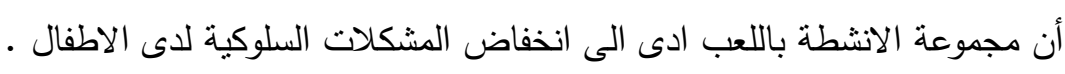

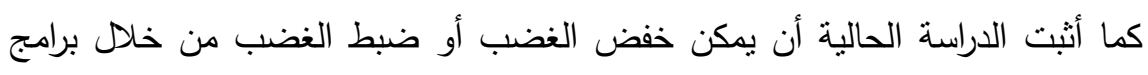

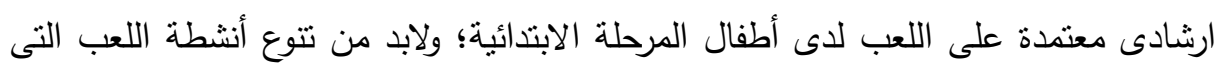

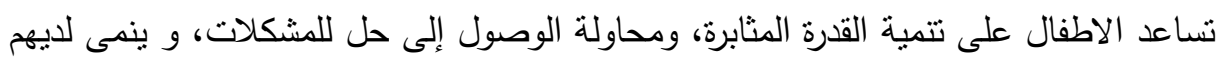
الوعى الاجتماعى والحياة التعاونية و خفض القلق والتوتر والانفعالات السلبية التى يستخدمها الاطفال عند ضبط الغضب لديها. رابعاً: مناقشة الفرض الثالث والرابع: يوجد فرق دال احصائيا بين متوسطى رثب لإبهان درجات المجموعة التجريبية لاى أطفال المرحلة الابتدائية فى التطبيقين القبلى والبعدى لمقياس الغضب بعد تطبيق البرنامج لصالح التطبيق البعدى فى البيئتين العشوائية والحضرية.

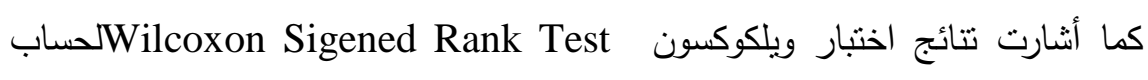

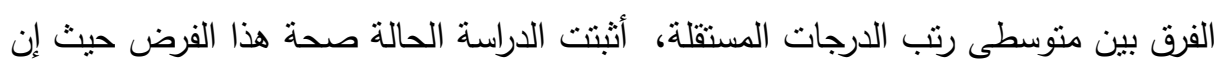
أفراد المجموعة التجريبية قبل نطبيق البرنامج الارشادى باللعب عيلهم كانوا منلهم منل أفراد

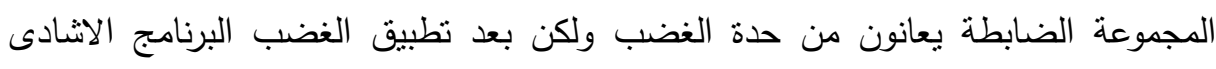

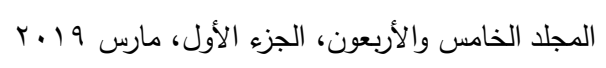


باللعب أصبحت المجموعة التجريبية أكثر فعالية مما ساعد على ضبط الغضب لديهم بشكل جيد.

كما اتفقت الدراسات السابقة منها دراسة (2003) Scheckner قد أظهرت النتائج أن الطلبة الذين نم اختيارهم لتطبيق البرنامج تعلموا كيف يهدأ الغضب، تعلموا طرق واقعية

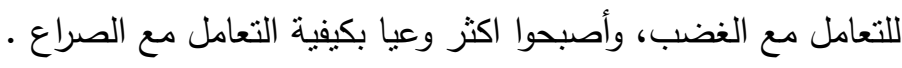
كما اتفقت دراسة (2006) Kapsch فعالية البرنامج العب الدامى على حل المشكلات النشاطك الزائد والغضب حيث انخفض النشاط الرائد والغضب لدى أطفال الروضة والصف على الصف

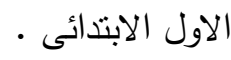
كما اتفقت داسة محمد عبد الرحمن (7 (1) بوصلت النتائج إلى ان العلاج باللعب أدى التى

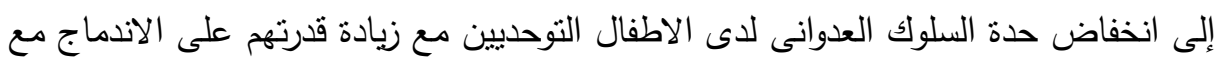

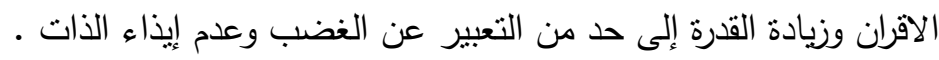

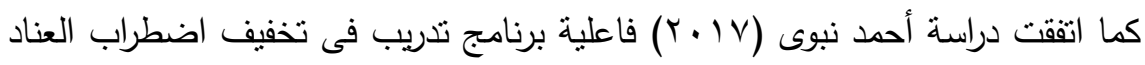
والمتحدى للتلاميذ الصم خامساً: مناقشة الفرض الخامس والسادس: لايوجد فرق دال إحصائيا بين متوسطى

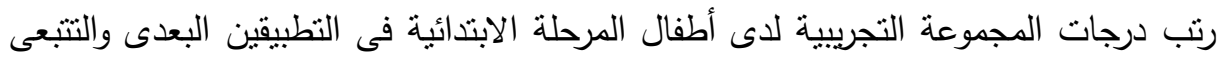

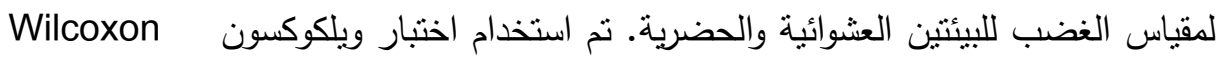
كساب الفرق بين متوسطى رتب الدرجات المستقلة .

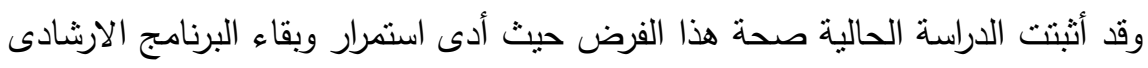

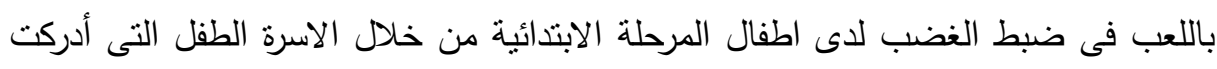

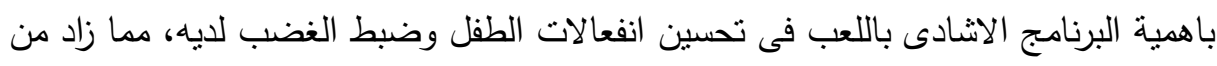

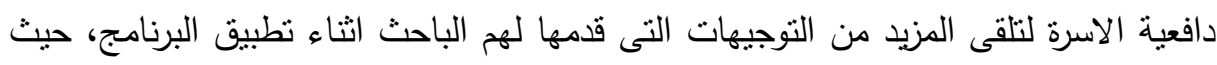

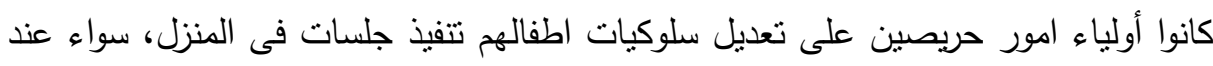

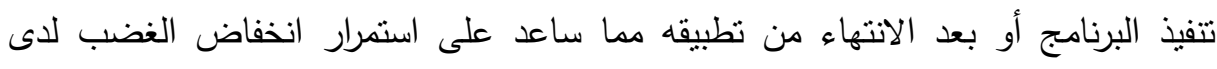

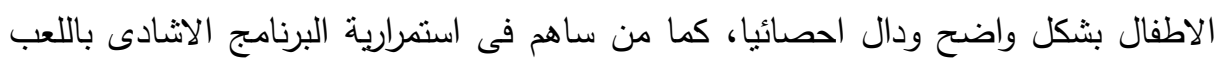

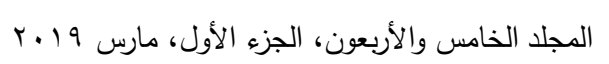


فى ضبط وتحسين الغضب لاى الاطفال المرحلة الابتدائية مديرين المدراس كانوا مهتمين

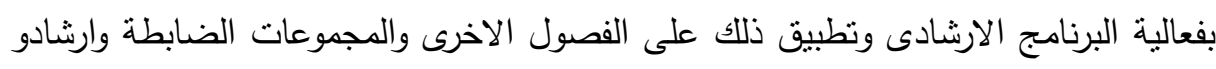

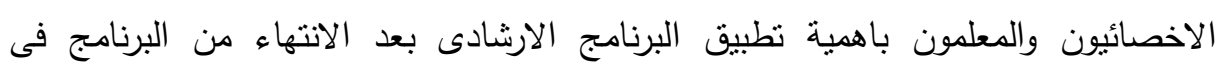

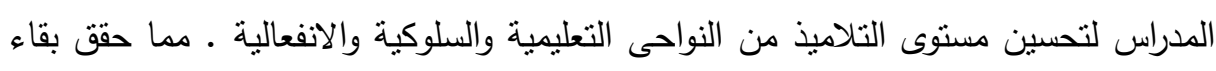

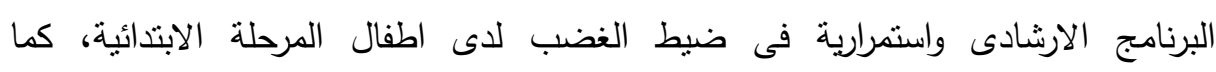

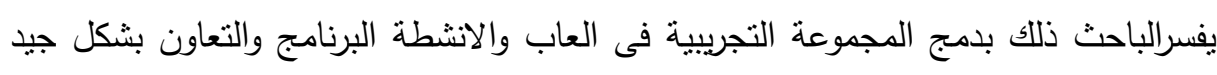
فى تحقيق البرنامج الاشادى وتعاون الاسرة مع الباحث والاخصائيين فى المدرسة.

\section{اللجروسياهت}

1- الاستفادة من البرنامج الارشادى الذى تم اعداده فى الدراسة الحالية، والذى تم تطبيقه

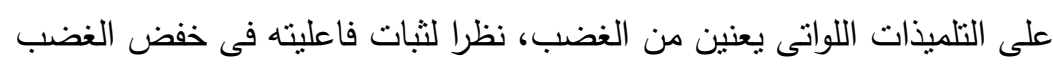

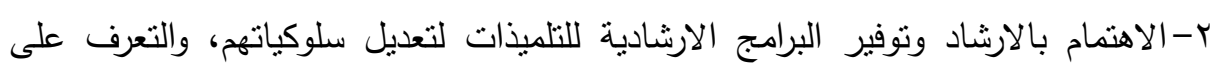

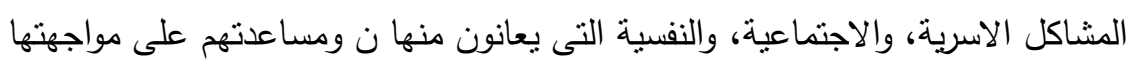

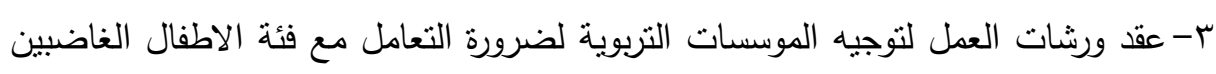

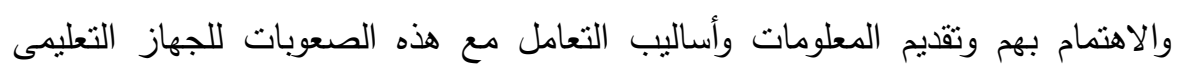
ومديرى المدارس.

ع-استخدام برامج إرشادية اكثر قائمة على اللعب لضبط الغضب على فئات عمرية اخر ه-تطوير البرامج الارشادية سواء كانت جماعية أو فردية قائمة على اللعب لتحسين التين التعبير عن المشاعر بطريقة صحيحة 1-استخدام البرامج الارشادية باللعب كإجراء وقائى ونمائى وعلاجى مع المشكلات الاخرى الإئه غير الغضب لاى الاطفال 


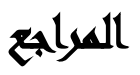

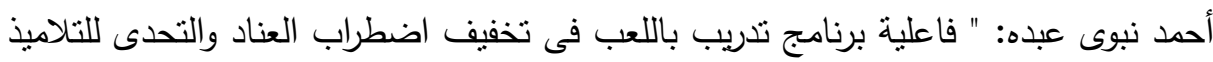

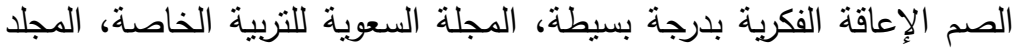

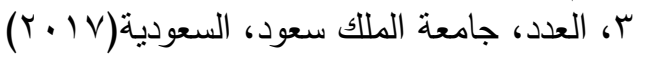

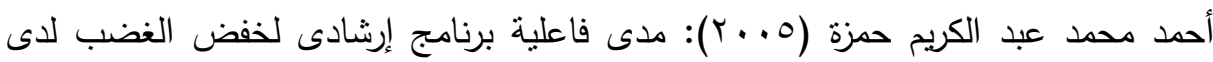

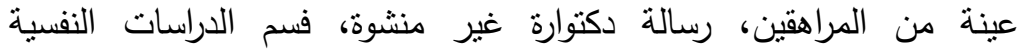

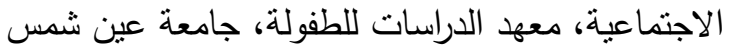

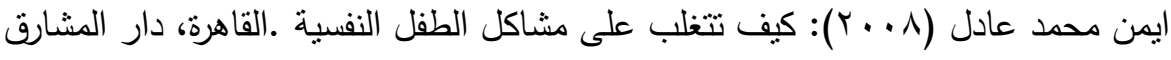

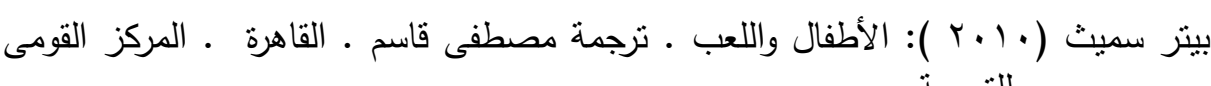
للترجمة (ب (ب)

حامد عبد السلام زهران (0. . ب): الصحة النفسية والعلاج النفسى ـ طء .القاهرة ، عالم الكتب

حامد عبد السلام زهران(99v (1)): الصحة النفسية والعلاج النفسى، القاهرة، عالم الكتب

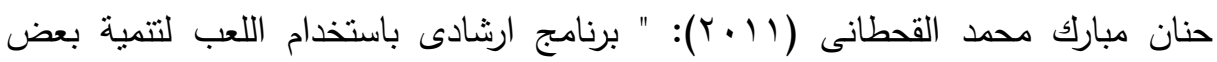

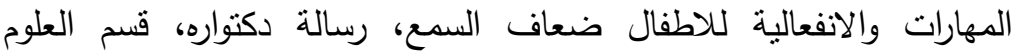
النفسية، كلية رياض الطفال، النفال جامعة القاهرة

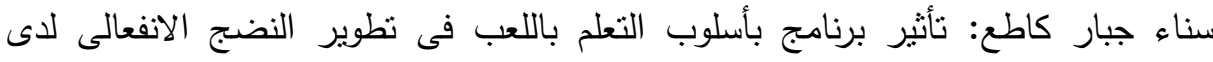

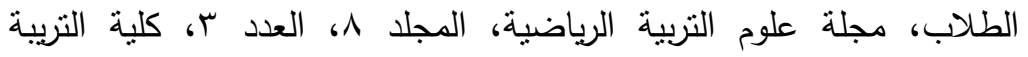

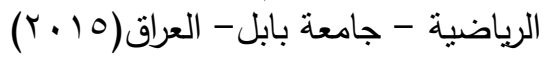

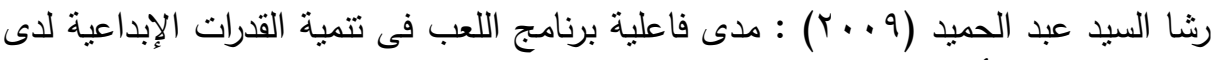

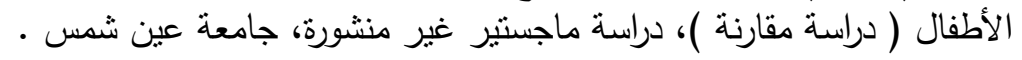

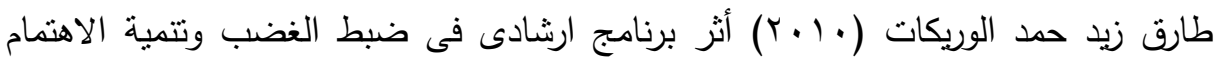

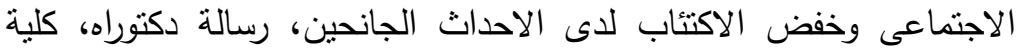

$$
\text { الدراسات العليا، الجامعة الاردنية، الاردن . الإحن }
$$

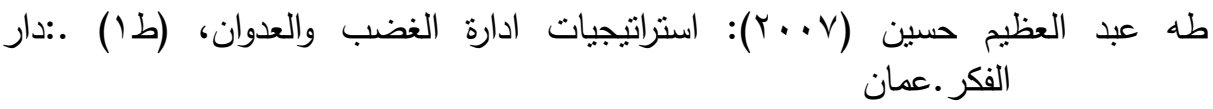




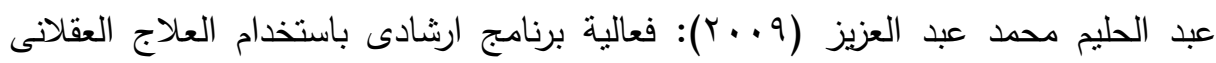

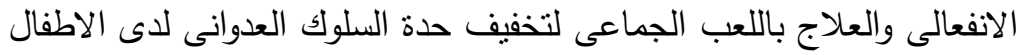

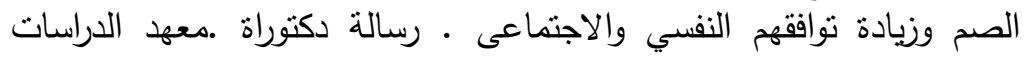
التربوية .جامعة القاهرة

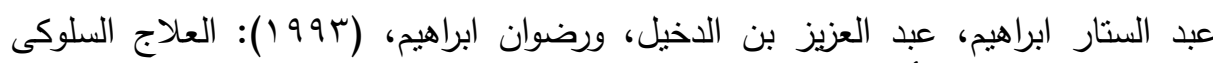

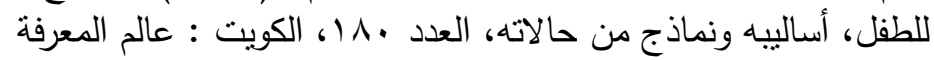

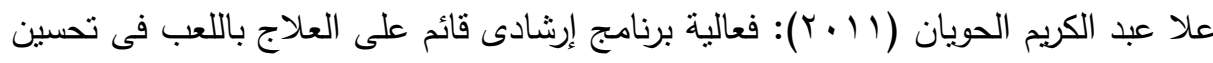

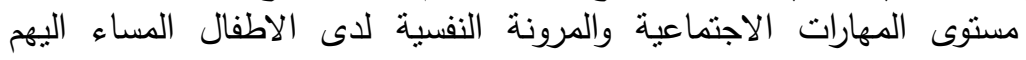

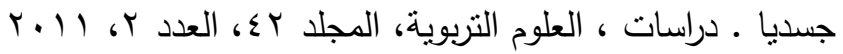

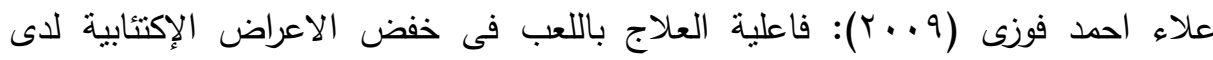
الاطفال ضعاف السمع ، رسالة ماجستير ـ كلية التربية ـ جامعة عين شعس.

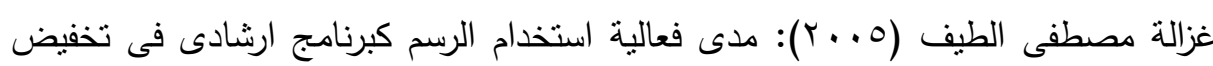

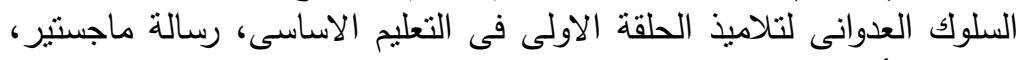

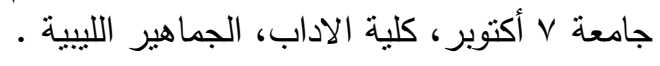

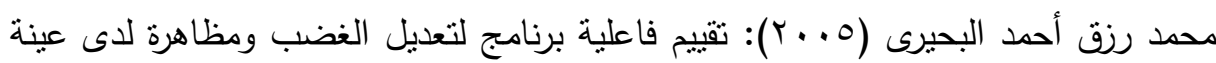

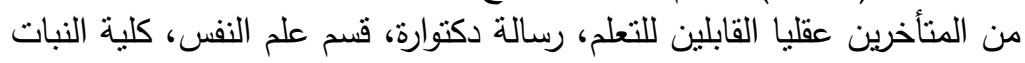

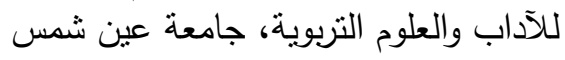

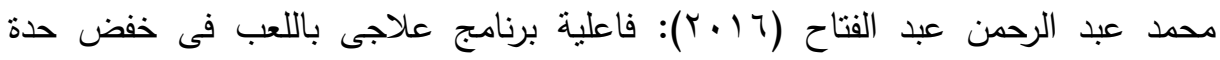

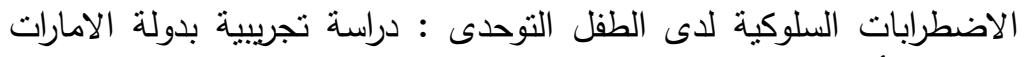

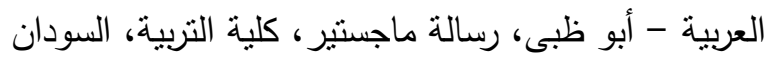
محمد محمد الحماحمى (999 (1)): فلسفة اللعب ـ القاهرة : مركز الكتاب للنشر النش

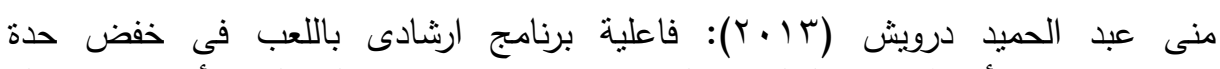

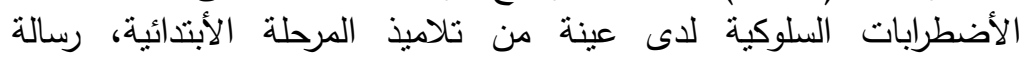

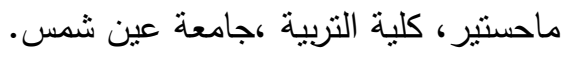

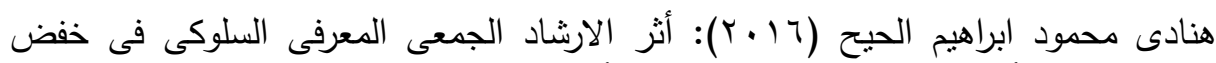

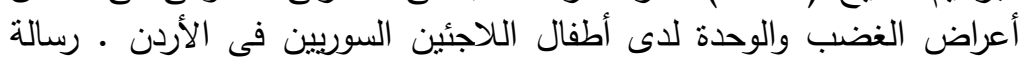

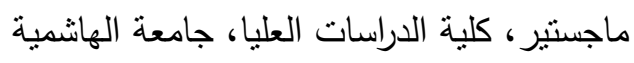




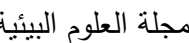

معهد الدراسات والبحوث البيئة - جامعة عين شمس لئس

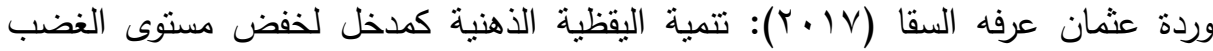

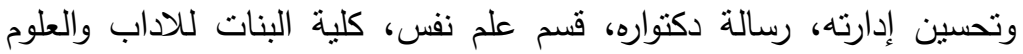

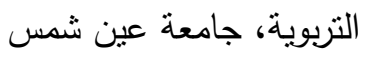

دليل العميل رقم ץ : مركز الرشد التخصصى، الطائف، السعودي

Bratton , Sue \& Ojiambo , Deborah (2014): Effects of Group Activity Play Therapy on Problem Behaviors of preadolescent Ugandan Orphans . Journal of Counseling \& Development . $92,335-365$.

Kapsch , A. (2006): The Effect of Dramatic Play on Childrens Graphic Representation of Emotion Doctor of Philosophy in the Department OF Educational Psychology in the College of Education . Georgia state University, Atlanata, Georgia .

Oz, F . Aysan , F (2011): The effect of anger management training on anger coping and communication skills of adolescents .international online Journal of Educational Sciences , (1), 343-369.

Tigge,P.1 (2010): Play therapy techniqes for African American elementary school-aged children diagnosed with oppositional defiant disorder . PhD. Capella University . united States .

Volter .J . S.I ,(2004): Compliance and Noncompliance in Anxious, Aggressive, and Socially Competent Children : the Impact of the Chlids Game on Child and Maternal Behavior Therapy . Summer 3 . 187, 495, 513 .

Zhou , Q. Main A . Wan, Y (2010): The relations of temperamental effortful control and anger/frustration to Chinese children $\mathrm{s}$ academic achievement and social adjustment . Journal of Educational Psychology , 102, 108-196.

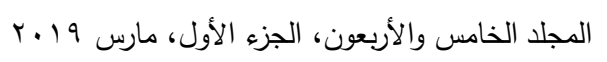




\title{
EFFECTIVENESS OF COUNSELLING PROGRAM USING PLYING TO CONTROL ANGER IN A SAMPLE OF PRIMARY STAGE CHILDREN ( STUDY IN DIFFRNT ENVIRONMENTS)
}

\author{
Mohamed, M. El Saied ${ }^{(1)}$; Tahani O. Moneeb $^{(2)}$; \\ Sherif, Seham, A. ${ }^{(3)}$ and Soheir, S. Abdel Gaid (2) \\ 1) Institute of Environmental Studies \& Research, Ain Shams \\ University 2) Faculty of Education, Ain Shams universty 3) Faculty of \\ Education, Helwin universty
}

\begin{abstract}
The aim of the present study to identify effective instructional program play to adjust the anger I have sample kids primary school, The study of fifth and sixth graders from two dowl Ismailia governorate school as urban environment., Omar Bin Khattabschool Qantara East city of Ismailiya as random environment., The sample consisted of four groups, first set in random environment, of 30 pupils and students were divided into two groups (15)experimental and(15) contral group , , The second sample consisted of urban environment (26) pupils and students were divided into two groups (13) and experimental (13) contral group, Fifth and sixth row from the age (11-12) years, and use the children's anger scale int primary researcher Setup, Indicative programme play (int), social and economic level form (Abdulaziz person 2006), Where the two groups have undergone random fact and indicative programme urban play (18) two and a half session. Use int statistical methods, Wilcoxon Rank Wilcoxon Sigened Test to calculate the difference between the middle ranks groups linked, test man Whitney Mann-Whitney Test to calculate the difference between the middle ranks of independent groups, and influenced the study showed, There is a statistically significant difference between the two grades levels medium officer and experimental elementary children in the 226

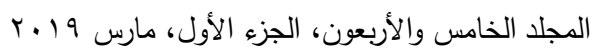




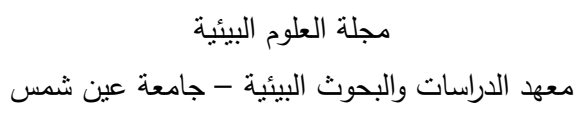

application post for a measure of anger for the pilot group for the environment. There is a difference between Med statistically control and experimental groups grades grades in primary school children in the application post for a measure of anger for the pilot group to the urban environment.,, There is a statistically significant difference between middle-grade children experimental group grades primary tribal applications walbadi to measure anger after software application for application post for random environment. There are statistically significant difference between middle-grade children experimental group grades primary tribal applications walbadi to measure anger after software application for application post for urban environment, No statistically significant difference between middle-level grades of experimental group for DIY elementary children in dimensional applications and tracing to measure anger random environment. No statistically significant difference between middle-grade children experimental group grades elementary in dimensional applications and tracing to measure anger of the urban environment ,", This means that the play indicative programme was effective in controlling and reducing the level of anger among primary school children. 